Article

\title{
Synthesis of Zeolites from Greek Fly Ash and Assessment of Their Copper Removal Capacity
}

\author{
Aikaterini Vavouraki ${ }^{1, *}$, Georgios Bartzas ${ }^{2}\left(\mathbb{D}\right.$ and Konstantinos Komnitsas ${ }^{1}$ (D) \\ 1 School of Mineral Resources Engineering, Technical University of Crete, 73100 Chania, Greece; \\ komni@mred.tuc.gr \\ 2 School of Mining and Metallurgical Engineering, National Technical University of Athens, \\ 15780 Athens, Greece; gbartzas@metal.ntua.gr \\ * Correspondence: avavouraki@isc.tuc.gr; Tel.: +30-28210-06167
}

Received: 17 August 2020; Accepted: 21 September 2020; Published: 24 September 2020

\begin{abstract}
The objective of this study was to synthesize zeolites through fusion of lignite fly ash and $\mathrm{NaOH}$ or $\mathrm{KOH}$ pellets at $600^{\circ} \mathrm{C}$ and assess their removal efficiency in terms of decontamination of solutions containing $\mathrm{Cu}(\mathrm{II})$ ions. The removal efficiency of the produced zeolites was tested in batch kinetic experiments using different zeolites and $\mathrm{Cu}$ (II) ion concentrations. Experimental data revealed that zeolites synthesized with the use of $\mathrm{NaOH}$ exhibited higher removal efficiency compared with those synthesized with the use of $\mathrm{KOH}$. Kinetic data showed that the pseudo-second-order equations described well the removal process. Copper removal was mainly accomplished through the concerted action of chemisorption and intraparticle diffusion. Analytical techniques involving XRF, XRD, FTIR, SEM/EDS and XPS were used for the characterization and morphology analysis of the produced zeolites. SEM/EDS confirmed the presence of copper on the zeolite surface. XPS spectra of Cu2p at $934.3 \mathrm{eV}$ proved the presence of $\mathrm{Cu}$ (II) oxidation state, confirming the possible formation of $\mathrm{CuO}$ and/or $\mathrm{Cu}-\mathrm{Cl}$.
\end{abstract}

Keywords: fly ash; synthetic zeolites; copper removal; kinetics; XPS

\section{Introduction}

The dependence of the society on coal-based energy is still high in most countries [1] Today, coal provides almost 30\% of the world's non-renewable primary energy, whereas this figure is anticipated to drop by only $3-4 \%$ within the next few years. As a result of coal combustion in power plants, huge quantities of coal fly ash (FA) are generated causing immense management and environmental problems [2]. The generation of electricity in Greece mainly depends ( 73\%) on the combustion of local lignite, while the most important lignite centers in the country are Ptolemais-Amynteon and Megalopolis, which are located in West Macedonia and Peloponnese regions, respectively. Annually, the electricity generation power plants in Greece burn approximately 64 million tons of lignite and produce nearly 13 million tons of FA [3].

Fly ash mainly consists of aluminosilicates $\left(\mathrm{Al}_{2} \mathrm{O}_{3}\right.$ and $\left.\mathrm{SiO}_{2}\right), \mathrm{Fe}_{2} \mathrm{O}_{3}$, and $\mathrm{CaO}$ and may exhibit toxicity and/or cause environmental and health impacts if not properly managed or disposed of in abandoned lignite quarries and other improper sites [4]. Due to its pozzolanic properties, FA can be used in a number of applications including partial replacement of cement during the production of concrete [5], the production of ceramics and glass-ceramics [6], and the production of alkali-activated materials (AAMs; so-called "inorganic polymers" or "geopolymers"). AAMs can be also used as backfill in exhausted underground mines [7,8], as soil amendment [9], as catalysts in various environmental applications [10], in wastewater treatment [11], as well as for the stabilization of sludge(s) and other hazardous wastes [12]. 
An interesting option to utilize FA includes its conversion to zeolites, which are microporous hydrated aluminosilicate materials and have high added value [13]. Zeolites have an infinitely extended three-dimensional network consisting of $\left(\mathrm{SiO}_{4}\right)^{4-}$ and $\left(\mathrm{AlO}_{4}\right)^{5-}$ tetrahedra linked by shared oxygen atoms. The voids and internal channels present in the zeolite network allow easy access and fast diffusion rates of molecules, thus rendering the zeolites as efficient adsorbents for various contaminants [14]. Zeolites can be used in several environmental applications, including removal of heavy metal ions and other inorganic and organic contaminants from municipal, agricultural, mining, metallurgical, and various other industrial wastewaters [15-21]. Zeolites may also be used to remove inorganic and organic air pollutants, including nitrogen oxides (NOx) and volatile organic compounds (VOCs) [22-24]. Finally, they can be used for the removal, fixation, and control of contaminants and transport of nutrients in soils and sediments [25-28].

The main aims of this study were the production of zeolites through fusion of a low-calcium Greek lignite FA with the use of $\mathrm{NaOH}$ and $\mathrm{KOH}$, and the determination of their high removal capacity in terms of removing high concentrations of $\mathrm{Cu}$ (II) ions from solutions and their morphology using several analytical techniques including surface-sensitive X-ray photoelectron spectroscopy (XPS).

\section{Materials and Methods}

\subsection{Raw Materials and Reagents}

The FA used for the synthesis of zeolites was obtained from the Greek thermoelectric power plant of Megalopolis (Peloponnese, Greece). Prior to use, FA was pulverized in a Sepor-type rod mill (Sepor, Los Angeles, CA, USA) to a particle size less than $200 \mu \mathrm{m}$. For the fusion tests, analytical-grade $\mathrm{NaOH}$ or $\mathrm{KOH}$ pellets (Fluka) were used. For the kinetic tests, solutions of copper nitrate trihydrate and sodium chloride were prepared from the corresponding crystalline solids $\mathrm{Cu}\left(\mathrm{NO}_{3}\right)_{2} \cdot 3 \mathrm{H}_{2} \mathrm{O}$ (Alfa Aesar, Haverhill, MA, USA) and $\mathrm{NaCl}$ (Panreac, Barcelona, Spain), respectively, with the use of deionized water (Zalion, London, UK).

\subsection{Synthesis of Zeolites}

Zeolites were synthesized through fusion of FA with $\mathrm{NaOH}$ or $\mathrm{KOH}$ in an N-8L SELECTA oven (J.P. Selecta, Barcelona, Spain) at $600{ }^{\circ} \mathrm{C}$ for $1 \mathrm{~h}$, using a heating rate of $\sim 10^{\circ} \mathrm{C} \cdot \mathrm{min}^{-1}$. The mass ratios of FA to $\mathrm{NaOH}$ or $\mathrm{KOH}$ were 1:1 (for the production of ZFA1Na and ZFA1K zeolites, respectively) and 1:1.5 (for the production of ZFA1.5Na and ZFA1.5K zeolites, respectively). The produced zeolites were first cooled at room temperature and then pulverized and homogenized using an agate mortar and pestle. The pulverized material was mixed with deionized water in a $500 \mathrm{~mL}$ conical flask, using a solid-to-liquid ratio of $20 \% w / v$, and stirred for $12 \mathrm{~h}$ with the use of a magnetic stirrer (Agimatic-ED; J.P. Selecta). After that, the suspension was further incubated under stirring at $30{ }^{\circ} \mathrm{C}$ for 4 days. The synthetic zeolites were obtained after centrifugation in a bench top Nüve NF1200 centrifuge (Nüve, Ankara, Turkey) and drying at $80^{\circ} \mathrm{C}$ in a laboratory oven (ON-02G; Jeio Tech, Seoul, Korea) for $24 \mathrm{~h}$. Prior to use, synthetic zeolites were washed with $0.1 \mathrm{M} \mathrm{HCl}$.

\subsection{Kinetic Studies}

First, the removal efficiency of the produced $\mathrm{Na}$ (ZFA1Na and ZFA1.5Na) and K zeolites (ZFA1K and ZFA1.5K) was tested, using a zeolite dosage of $0.5 \mathrm{~g} \cdot \mathrm{L}^{-1}$ and different initial Cu(II) concentrations, varying from 50 to $400 \mathrm{mg} \cdot \mathrm{L}^{-1}$.

Then, kinetic experiments were carried out to assess the effect of initial $\mathrm{Cu}$ (II) concentration (45-200 $\left.\mathrm{mg} \cdot \mathrm{L}^{-1}\right)$, using both the Na-based zeolites at dosages $0.3,0.5,1.0$, and $1.5 \mathrm{~g} \cdot \mathrm{L}^{-1}$, on the degree of copper removal. The suspensions ( $3 \mathrm{~mL}$ aliquots) were taken at predefined time intervals $(5,10,15$, 20, 30, and $60 \mathrm{~min})$, filtered using syringe filters $(0.45 \mu \mathrm{m}$ pore size, Polytetrafluoroethylene (PTFE), Chromafil) and analyzed with inductively-coupled plasma mass spectrometry (ICP-MS) in order to determine the residual metal ion concentration. All tests were carried out in conical flasks, with an 
operating volume of $250 \mathrm{~mL}$, at a constant ionic strength of $0.1 \mathrm{M} \mathrm{NaCl}$ and room temperature $\left(25 \pm 1^{\circ} \mathrm{C}\right)$ under stirring at $600 \mathrm{rpm}$ using a magnetic stirrer (Agimatic-ED; J.P. Selecta, Barcelona, Spain).

The evolution of suspension $\mathrm{pH}$ was also determined using a Hanna $211 \mathrm{pH} / \mathrm{Eh}$ meter (Hanna, Bedfordshire, $\mathrm{UK}$ ); it is mentioned that $\mathrm{pH}$ is relatively constant during the implementation of the tests $\left(\mathrm{pH}_{\text {initial }} 4.2\right.$ and $\mathrm{pH}_{\text {final }}$ 5.5). At such $\mathrm{pH}$ values, no precipitation of $\mathrm{Cu}(\mathrm{OH})_{2}$ is anticipated. However, atacamite and $\mathrm{CuO}$ formation may occur according to PHREEQC code v.3.4.0 [29] simulations carried out using the minteq.v4 database and shown in the Supplementary Material (Figure S1). In this context, the calculation of saturation indices (SI) at different $\mathrm{pH}$ values revealed that the solution was undersaturated with respect to $\mathrm{Cu}(\mathrm{OH})_{2}$ and $\mathrm{Cu}_{2}(\mathrm{OH})_{3} \mathrm{NO}_{3}$, and supersaturated with respect to atacamite $\left(\mathrm{Cu}_{2}(\mathrm{OH})_{3} \mathrm{Cl}\right)$ and $\mathrm{CuO}$ at $\mathrm{pH}$ values above 4.9 and 5.3, respectively. A negative value of the saturation index indicates that the solution is undersaturated and the solid phase tends to dissolve, whereas a positive value indicates a clear tendency for precipitation. A value close to zero suggests that the solution is in equilibrium with the solid phase [30].

The removal capacity of zeolites was calculated by using Equation (1), while the removal degree $(\% R D)$ of copper ions from aqueous solutions was calculated by using Equation (2):

$$
\begin{gathered}
q_{t}=\frac{V\left(C_{0}-C_{t}\right)}{m} \\
\% R D=\frac{\left(C_{0}-C_{t}\right)}{C_{0}} \%
\end{gathered}
$$

where $q_{t}$ is the mass of removed $\mathrm{Cu}(\mathrm{II})$ ion per unit mass of zeolite $\left(\mathrm{mg}^{-\mathrm{g}^{-1}}\right) ; V$ is the volume of the aqueous phase (L); $C_{0}$ and $C_{t}$ are the initial and final $\mathrm{Cu}(\mathrm{II})$ ion concentrations $\left(\mathrm{mg} \cdot \mathrm{L}^{-1}\right)$, respectively; and $m$ is the mass of zeolite used (g).

The linearized kinetic models investigated in this study were the pseudo-first (Equation (3)) and pseudo-second-order models (Equation (4)) [31,32].

$$
\begin{gathered}
\log \left(q_{e}-q_{t}\right)=\log q_{e}-\frac{k_{1} t}{2.303} \\
\frac{t}{q_{t}}=\frac{1}{k_{2} q_{e}^{2}}+\frac{t}{q_{e}}
\end{gathered}
$$

where $q_{e}\left(\mathrm{mg} \cdot \mathrm{g}^{-1}\right)$ is the amount of solute removed per unit mass of zeolite at equilibrium; and $k_{1}\left(\mathrm{~min}^{-1}\right)$ and $k_{2}\left(\mathrm{~g} \cdot \mathrm{mg}^{-1} \cdot \mathrm{min}^{-1}\right)$ are the apparent rate constants for pseudo-first-order and pseudo-second-order kinetics, respectively. Additionally, the intraparticle diffusion model was examined according to Equation (5) [33]:

$$
q_{t}=K_{p} t^{0.5}+C
$$

where $K_{p}$ is the intraparticle diffusion rate constant $\left(\mathrm{mg} \cdot \mathrm{g}^{-1} \cdot \mathrm{min}^{-0.5}\right)$ and $C\left(\mathrm{mg} \cdot \mathrm{g}^{-1}\right)$ is a parameter related to the thickness of the boundary layer.

All experiments were carried out in duplicate and average values are given in the paper. It is important to note that all measured concentrations in similar tests were almost identical and the difference was $\pm 2 \%$.

\subsection{Analytical Techniques}

The chemical analysis of FA was performed using an X-ray fluorescence energy-dispersive spectrometer (Spectro XEPOS; Ametek Inc., Berwyn, PA, USA). X-ray diffraction (XRD) analyses were carried out with the use of Siemens D500 Diffractometer (Bruker D8-Focus powder diffractometer; Bruker, Karlsruhe, Germany), with nickel-filtered CuK radiation $(\lambda=1.5405 \AA)$. The Brunauer-Emmett-Teller (BET) surface area of the synthetic zeolites was determined using a NOVA surface area analyzer (Quantachrome Nova 2200 analyzer; Anton Paar Quanta Tec Inc., Boynton Beach, FL, USA). 
Prior to BET analysis, synthetic zeolites were pulverized and the particle size distribution was determined with the use of a Mastersizer S particle size analyzer (Malvern Instruments, Worcestershire, UK). The metal ion concentration in solution was determined with the use of inductively-coupled plasma mass spectrometry (ICP-MS) (Agilent Technologies 7500cx, Santa Clara, CA, USA).

A Fourier-transform infrared spectroscopy (FTIR) analysis was carried out on pellets produced after mixing a pulverized sample with $\mathrm{KBr}$ at a ratio of 1:100 w/w, using a Perkin Elmer Spectrum 1000 spectrometer (Perkin Elmer, Wellesley, MA, USA). A scanning electron microscopy (SEM) analysis was performed using a JEOL 6380LV scanning electron microscope (JEOL, Tokyo, Japan) equipped with an energy-dispersive X-ray spectroscopy (EDS) microanalysis system (INCA Energy 250; Oxford Instruments, Abington, UK) under low vacuum conditions (using pressure at $30 \mathrm{~Pa}$, accelerating voltage at $20 \mathrm{kV}$, and working distance at 10-12 mm). The SEM/EDS examination was performed using a beam current and a beam size of $1 \mathrm{nA}$ and $1 \mu \mathrm{m}$, respectively, on the sample. In each EDS quantification conducted, a dwell time of $30 \mathrm{~s}$ was applied.

X-Ray photoelectron spectroscopy (XPS), which enables elucidation of ion uptake and provides information on its chemical state [34-37], was carried out in an ultra-high vacuum chamber (UHV) equipped with an X-ray Al/Mg gun and a Phoibos 100 1D-DLD energy analyzer (Specs GmbH, Berlin, Germany). An unmonochromatized $\mathrm{MgK} \alpha$ line at $1253.6 \mathrm{eV}$ and an analyzer pass energy of $10 \mathrm{eV}$, giving a full width at half maximum (FWHM) of $0.85 \mathrm{eV}$ for the $\mathrm{Ag} 3 \mathrm{~d} 5 / 2$ peak, was used in all XPS measurements. For spectra identification and fitting, the commercial software SpecsLab Prodigy (Specs GmbH, Berlin, Germany) was used. In this study, the atomic concentrations were calculated from the corresponding peak areas of $\mathrm{Cu} 2 \mathrm{p}, \mathrm{Si} 2 \mathrm{p}, \mathrm{Al} 2 \mathrm{p}$, and Na1s. Regarding $\mathrm{Cu}$, peak fitting of the $\mathrm{Cu} 2 \mathrm{p}$ spectrum revealed the presence of $\mathrm{Cu}$ ions on the chosen synthetic zeolite (ZFA1Na).

\section{Results and Discussion}

\subsection{Raw Material and Zeolite Characterization}

Table 1 shows the chemical composition of the FA used, while Figure 1 presents the mineralogical composition of the FA and the produced zeolites. It can be seen from Table 1 that the major oxides of FA were $\mathrm{SiO}_{2}, \mathrm{CaO}, \mathrm{Al}_{2} \mathrm{O}_{3}$, and $\mathrm{Fe}_{2} \mathrm{O}_{3}$ and since the content of $\mathrm{SiO}_{2}+\mathrm{Al}_{2} \mathrm{O}_{3}+\mathrm{Fe}_{2} \mathrm{O}_{3}$ was $\geq 50 \%$ (i.e., 66.3\%), the FA was classified as class $\mathrm{C}$ [38]. The $\mathrm{SO}_{3}$ concentration (3.4\% wt) and the loss on ignition (LOI; $3.9 \% \mathrm{wt}$ ) were lower than the maximum values of $5 \% \mathrm{wt}$ and $6 \% \mathrm{wt}$, respectively, indicated for class $\mathrm{C}$ fly ashes. The Si/Al molar ratio in FA was 2.1.

Table 1. Chemical composition (wt \%) of fly ash (FA).

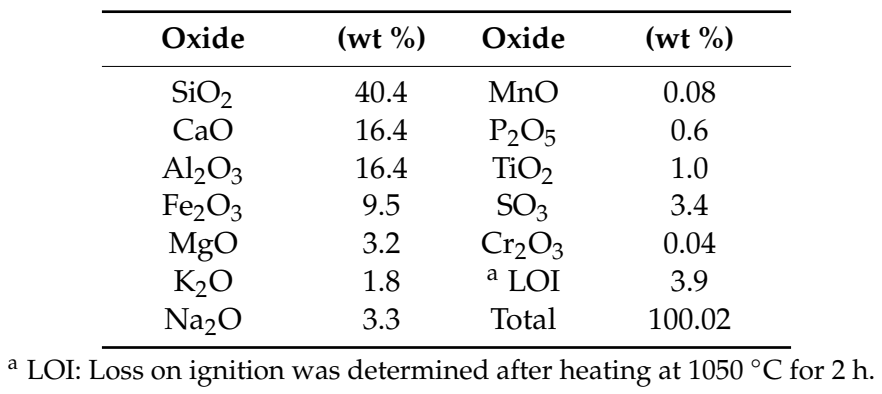

As shown in Figure 1, the main mineral phases present in FA were quartz and albite, while X-and A-type zeolites, sodium aluminum silicate hydrate, faujasite, and sodalite were clearly detected in ZFA1Na and ZFA1.5Na zeolites. Based on the XRD results, the ZFA1K and ZFA1.5K zeolites contained relatively low amount of $\mathrm{F}$ zeolite only. These results were in agreement with several earlier studies, which indicated that $\mathrm{NaOH}$ is a more efficient fusion agent compared with $\mathrm{KOH}$ for the production of zeolites [39-42].

Table 2 shows the particle size (in $\mu \mathrm{m}$ ) and the BET surface area (in $\mathrm{m}^{2} \cdot \mathrm{g}^{-1}$ ) of the produced synthetic zeolites. All zeolites had quite similar sizes (as indicated by the $\mathrm{d}_{50}$ values), which were 
very fine and varied between 11 and $21 \mu \mathrm{m}$. The surface area of the $\mathrm{K}$ zeolites was almost double $\left(\sim 21.7 \mathrm{~m}^{2} \cdot \mathrm{g}^{-1}\right)$ compared with the surface area of the Na zeolites $\left(\sim 15.3 \mathrm{~m}^{2} \cdot \mathrm{g}^{-1}\right)$, while the surface area of the FA was $8.3 \mathrm{~m}^{2} \cdot \mathrm{g}^{-1}$; the particle size of FA was $<200 \mu \mathrm{m}\left(d_{50}=35 \mu \mathrm{m}\right)$. Figure 2 shows the FTIR spectra of the $\mathrm{Na}$ and $\mathrm{K}$ zeolites as well as that of FA for comparison.

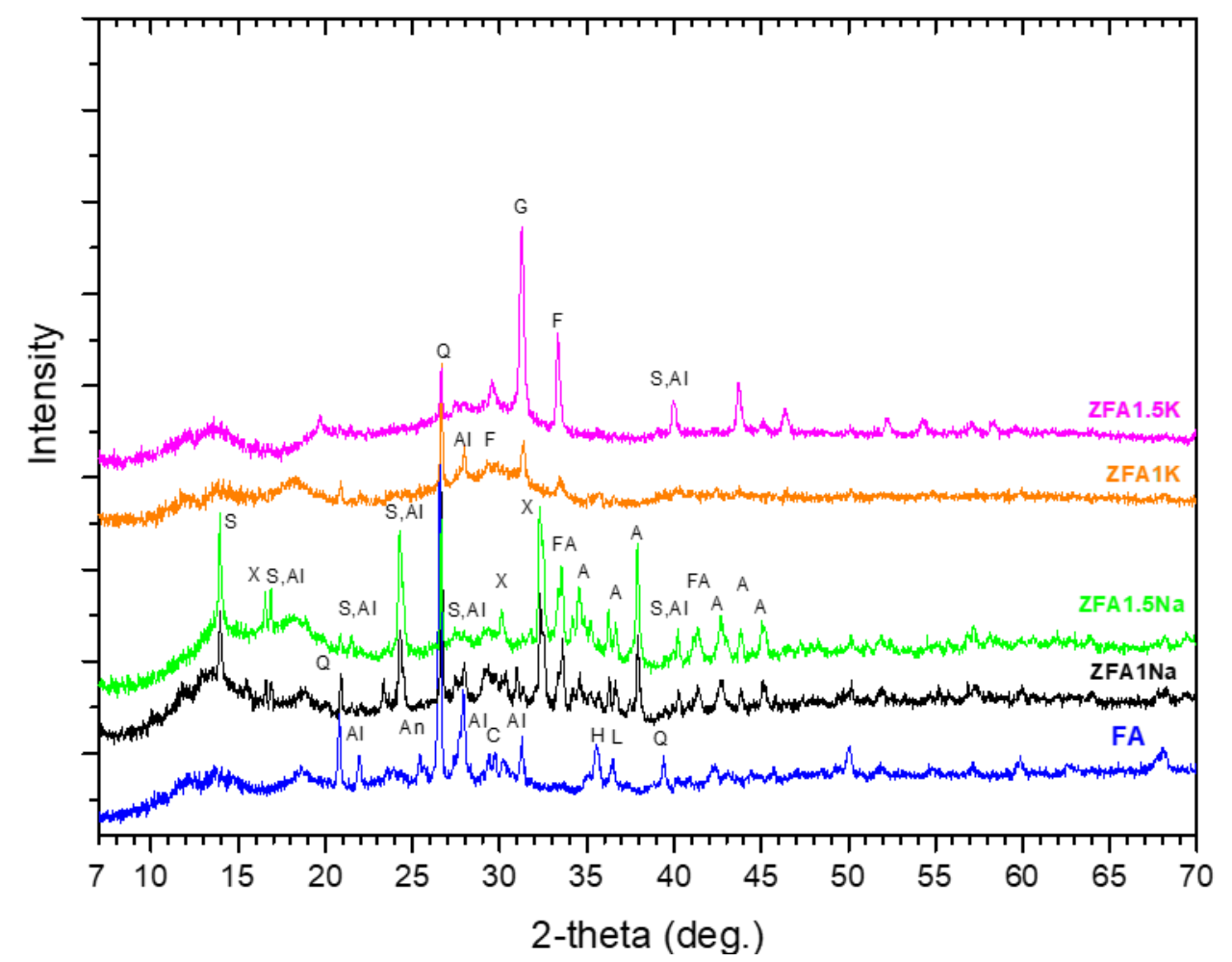

Figure 1. XRD patterns of FA, Na zeolites (ZFA1Na and ZFA1.5Na), and K zeolites (ZFA1K and ZFA1.5K). $\mathrm{Q}$, quartz $\left(\mathrm{SiO}_{2}\right) ; \mathrm{Al}$, albite $\left(\mathrm{NaAlSi}_{3} \mathrm{O}_{8}\right) ; \mathrm{G}$, gehlenite $\left(\mathrm{Ca}_{2} \mathrm{Al}_{2} \mathrm{SiO}_{7}\right) ; \mathrm{An}$, anhydrite $\left(\mathrm{CaSO}_{4}\right) ; \mathrm{H}$, hematite $\left(\mathrm{Fe}_{2} \mathrm{O}_{3}\right)$; L, lime $(\mathrm{CaO}) ; \mathrm{C}$, calcite $\left(\mathrm{CaCO}_{3}\right) ; \mathrm{X}$, xeolite $\mathrm{X}\left(\mathrm{NaAlSi}_{1.23} \mathrm{O}_{4.46} \cdot 3.07 \mathrm{H}_{2} \mathrm{O}\right)$; A, zeolite A $\left(\mathrm{NaAlSi}_{1.1} \mathrm{O}_{4.2} \cdot 2.25 \mathrm{H}_{2} \mathrm{O}\right)$; $\mathrm{S}$, Al, sodium aluminum silicate hydrate $\left(\mathrm{Na}_{6} \mathrm{Al}_{6} \mathrm{Si}_{10} \mathrm{O}_{32} \cdot 12 \mathrm{H}_{2} \mathrm{O}\right)$; $\mathrm{S}$, sodalite $\left(\mathrm{Na}_{8} \mathrm{Al}_{6} \mathrm{Si}_{6} \mathrm{O}_{24} \mathrm{Cl}_{2}\right)$; FA, faujasite $\left(\mathrm{Na}_{2} \mathrm{Al}_{2} \mathrm{Si}_{3.3} \mathrm{O}_{8.8} \cdot 6.7 \mathrm{H}_{2} \mathrm{O}\right) ; \mathrm{F}$, Linde F zeolite $\left(\mathrm{KAlSiO}_{4} \cdot 1.5 \mathrm{H}_{2} \mathrm{O}\right)$.

Table 2. Particle size $(\mu \mathrm{m})$ and surface area $\left(\mathrm{m}^{2} \cdot \mathrm{g}^{-1}\right)$ of the synthetic zeolites.

\begin{tabular}{cccc}
\hline \multirow{2}{*}{ Zeolite Code } & \multicolumn{2}{c}{ Particle Size $(\boldsymbol{\mu m})$} & \multirow{2}{*}{ Specific Surface Area $\left(\mathbf{m}^{\mathbf{2}} \cdot \mathbf{g}^{\mathbf{- 1}} \mathbf{)}\right.$} \\
\cline { 2 - 3 } & Size & $\boldsymbol{d}_{\mathbf{5 0}}$ & \\
\hline ZFA1Na & $<191$ & 11.5 & 15.7 \\
ZFA1.5Na & $<118$ & 17.4 & 14.8 \\
ZFA1K & $<132$ & 11.3 & 21.9 \\
ZFA1.5K & $<223$ & 20.9 & 21.5 \\
\hline
\end{tabular}

The bands in the region 1090-990 and 750-550 $\mathrm{cm}^{-1}$ were common in all zeolites and indicated asymmetric and symmetric stretching vibration modes of Si-O-Si and Al-O-Si $[43,44]$. The asymmetric stretching vibration at $1090 \mathrm{~cm}^{-1}$ in FA became sharper and shifted to lower frequencies, i.e., $977 \mathrm{~cm}^{-1}$ and $998 \mathrm{~cm}^{-1}$, in $\mathrm{Na}$ and $\mathrm{K}$ zeolites, respectively, indicating the formation of zeolitic products. The vibration bands at 874,680 , and $631 \mathrm{~cm}^{-1}$ were more intense in the produced zeolites compared with raw FA. The band at $1440 \mathrm{~cm}^{-1}$, which was sharp for the zeolites, can be assigned to the stretching vibrations of O-C-O units. The peaks at $440 \mathrm{~cm}^{-1}$ can be attributed to bending vibration modes of Si-O-Si and O-Si-O in the FA and zeolite framework [45]. The broad band at $3500 \mathrm{~cm}^{-1}$ corresponded to stretching vibrations of adsorbed water and $\mathrm{O}-\mathrm{H}$ groups. The band at $1630 \mathrm{~cm}^{-1}$ can be assigned to bending vibrations of $\mathrm{O}-\mathrm{H}$ groups of water molecules [46]. 


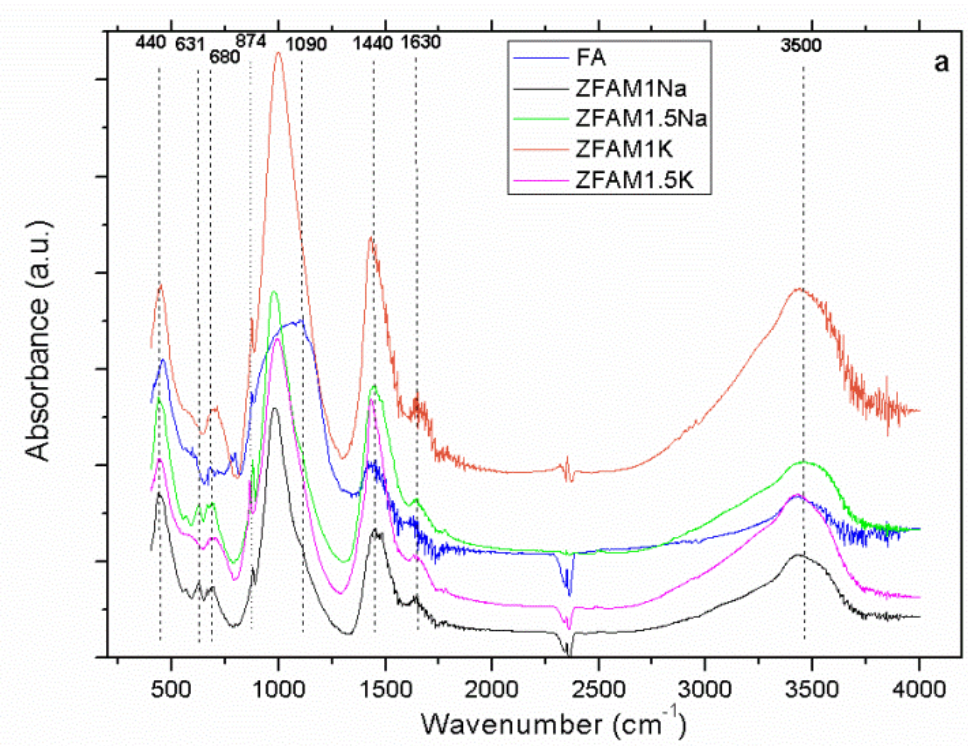

(a)

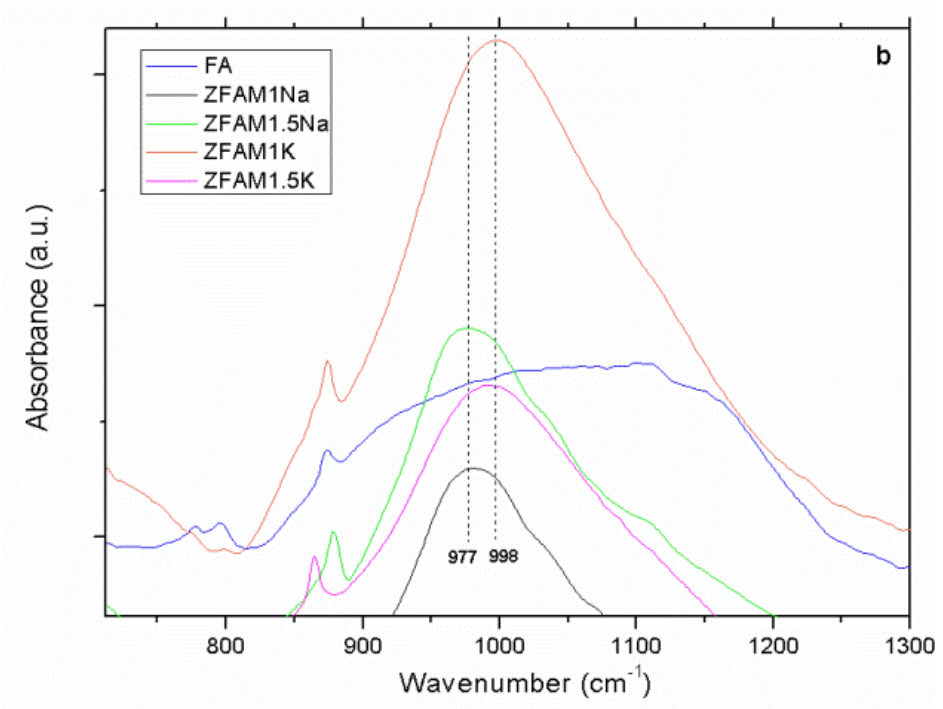

(b)

Figure 2. FTIR spectra (a) for all synthetic zeolites and raw FA; (b) zoomed area of the region between 800 and $1300 \mathrm{~cm}^{-1}$.

\subsection{Screening of $\mathrm{Na}$ and $\mathrm{K}$ Zeolites in Terms of Removal Efficiency}

In order to screen the produced Na zeolites (ZFA1Na and ZFA1.5Na) and K zeolites (ZFA1K and ZFA1.5K) in terms of their removal efficiency, tests were carried out using a zeolite dosage of $0.5 \mathrm{~g} \cdot \mathrm{L}^{-1}$ and different initial $\mathrm{Cu}$ (II) concentrations, varying from 50 to $400 \mathrm{mg} \cdot \mathrm{L}^{-1}$ (Figure 3).

$\mathrm{Na}$ zeolites showed higher removal efficiency compared with $\mathrm{K}$ zeolites, over the entire $\mathrm{Cu}$ (II) concentration range examined and especially at higher $\mathrm{Cu}$ (II) ion concentrations. For example, when the $\mathrm{Cu}$ (II) concentration was $200 \mathrm{mg} \cdot \mathrm{L}^{-1}$, the removal efficiency of ZFA1Na and ZFA1.5Na zeolites was $85 \%$ and $75 \%$, respectively, while the removal efficiency of ZFA1K and ZFA1.5K zeolites was significantly lower, $50 \%$ and $55 \%$, respectively. The removal efficiency of initial raw FA for the same $\mathrm{Cu}$ (II) ion concentration was less than $5 \%$ (data is not shown).

The higher removal efficiency of Na zeolites may be explained by the differences in their cation content and framework structure, compared with $\mathrm{K}$ zeolites. Sodium ions have higher hydrated radius $(3.58 \AA$ ) compared with potassium ions ( $3.31 \AA$ ); thus, they are less strongly attached through 
electrostatic interactions on the negatively charged surface of zeolites and can be more easily replaced by $\mathrm{Cu}(\mathrm{II})$ ions, as indicated in earlier studies $[47,48]$. In addition, it is known that the removal efficiency of zeolites depends on their effective pore size. As mentioned by Wang et al. [42], the pore sizes of zeolite A $(4.2 \AA)$, zeolite $X(7.4 \AA)$, and sodalite $(2.3 \AA)$, which are the main phases present in Na zeolites, are much larger than the unhydrated radius of $\mathrm{Cu}$ (II) ions $(0.82 \AA)$, thus favoring their removal; the hydrated radius of $\mathrm{Cu}(\mathrm{II})$ ions is $4.17 \AA$ [31]. On the other hand, the pore size of $\mathrm{F}$ zeolite (2.6 $\AA$ ), present in $\mathrm{K}$ zeolites, is also larger than the unhydrated radius of $\mathrm{Cu}$ (II) ions, but it is significantly smaller than the respective radii of the phases present in Na zeolites. Thus, higher removal efficiency of $\mathrm{Na}$ zeolites in comparison to $\mathrm{K}$ zeolites is anticipated. By taking into account these results, further removal studies were carried out with the use of ZFA1Na and ZFA1.5Na zeolites.

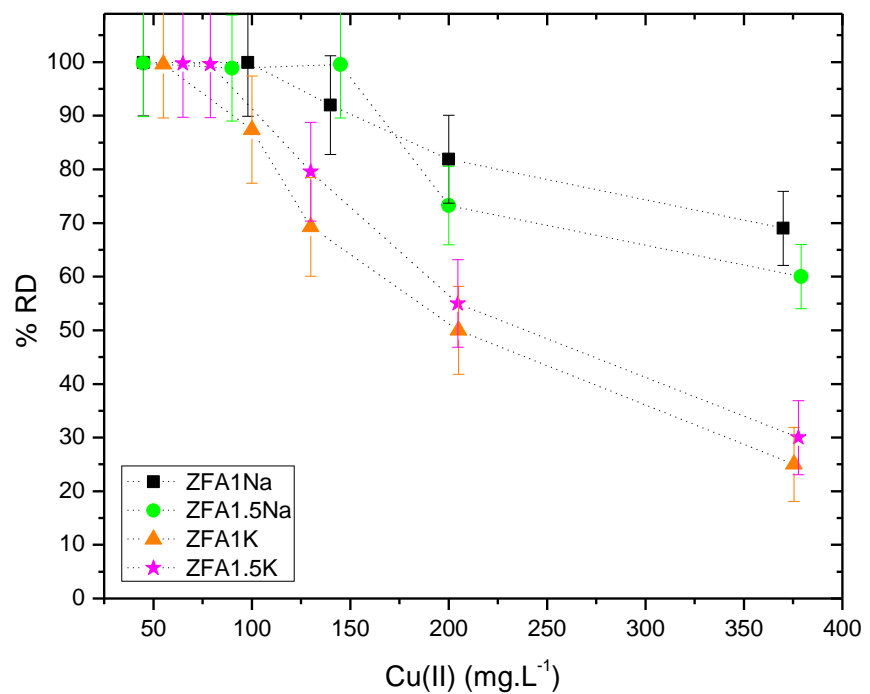

Figure 3. Removal efficiency of all zeolites (ZFA1Na, ZFA1.5Na, ZFA1K, and ZFA1.5K) for different initial $\mathrm{Cu}(\mathrm{II})$ ion concentrations (dosage, $0.5 \mathrm{~g} \cdot \mathrm{L}^{-1} ; 25^{\circ} \mathrm{C}$ ).

\subsection{Kinetic Studies}

\subsubsection{Effect of Initial $\mathrm{Cu}$ (II) Concentration}

The removal efficiency of both the Na zeolites is shown in Figure 4.
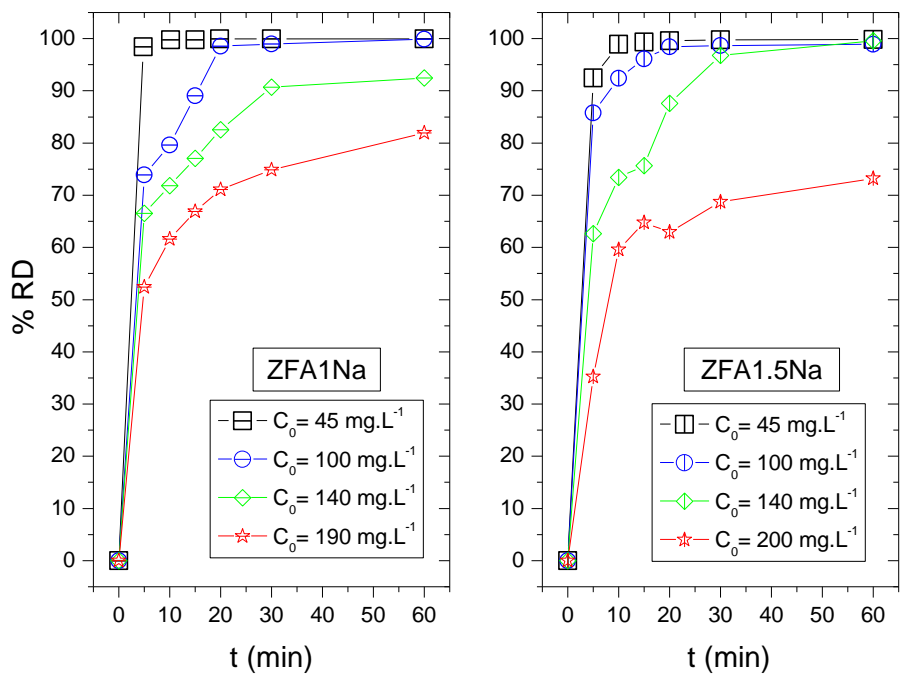

Figure 4. The removal degree (\%RD) of ZFA1Na and ZFA1.5Na zeolites (dosage of $0.5 \mathrm{~g} \cdot \mathrm{L}^{-1}$ ) as a function of the initial $\mathrm{Cu}(\mathrm{II})$ concentration $\left(45-200 \mathrm{mg} \cdot \mathrm{L}^{-1}\right)$. 
These results showed that the removal of $\mathrm{Cu}$ (II) ions for both ZFA1Na and ZFA1.5Na zeolites was complete and reached equilibrium within $20 \mathrm{~min}$ for the initial $\mathrm{Cu}$ (II) ion concentrations 45 and $100 \mathrm{mg} \cdot \mathrm{L}^{-1}$. When the initial $\mathrm{Cu}(\mathrm{II})$ ion concentration increased to $140 \mathrm{mg} \cdot \mathrm{L}^{-1}$, equilibrium was reached in almost $30 \mathrm{~min}$. Further increase in initial $\mathrm{Cu}$ (II) ion concentration to $200 \mathrm{mg} \cdot \mathrm{L}^{-1}$ resulted in lower removal degree; however, this remained higher than $70 \%$ for both the zeolites, ZFA1Na and ZFA1.5Na (82\% and $73 \%$, respectively).

\subsubsection{Effect of Zeolite Dosage}

Given that in the previous series the efficiency of both the Na zeolites was quite similar, ZFA1Na zeolite was selected to assess the effect of dosage $\left(0.3,0.5,1.0\right.$, and $\left.1.5 \mathrm{~g} \cdot \mathrm{L}^{-1}\right) \mathrm{on} \mathrm{Cu}(\mathrm{II})$ ion uptake. The $\mathrm{Cu}(\mathrm{II})$ ion concentration selected was $140 \mathrm{mg} \cdot \mathrm{L}^{-1}$ and the results are shown in Figure 5 . It can be seen from the data that the increase of dosage resulted in an increase in the removal degree due to the increase in the number of available binding sites. At the lowest dosage used $\left(0.3 \mathrm{~g} \cdot \mathrm{L}^{-1}\right)$, the removal efficiency of ZFA1Na was quite low, almost 50\%, while complete copper removal was attained after just $10 \mathrm{~min}$ at dosages $1-1.5 \mathrm{~g} \cdot \mathrm{L}^{-1}$.

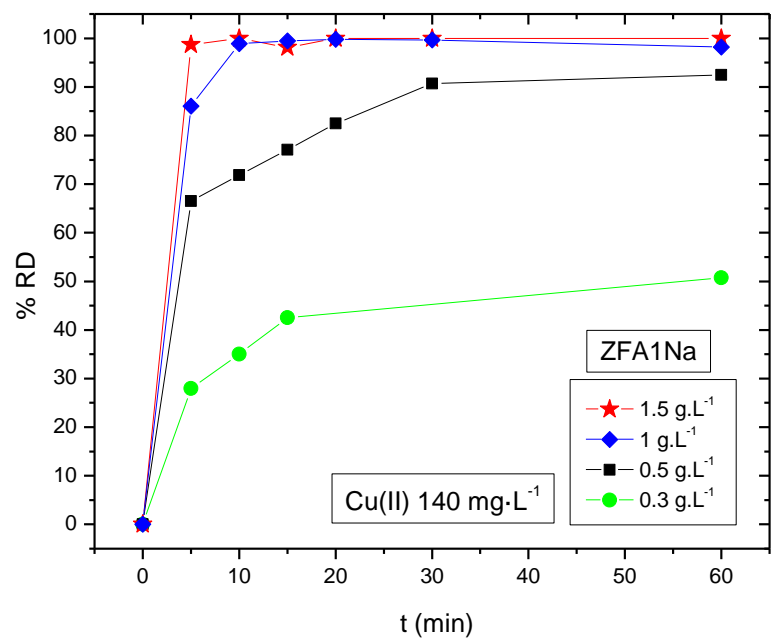

Figure 5. Effect of dosage $\left(0.3-1.5 \mathrm{~g} \cdot \mathrm{L}^{-1}\right)$ on the removal efficiency of ZFA1Na zeolite (initial $\mathrm{Cu}(\mathrm{II})$ concentration of $\left.140 \mathrm{mg} \cdot \mathrm{L}^{-1}\right)$.

\subsubsection{Evaluation of Kinetic Models}

Kinetic modeling was carried out to define the rate-determining step during removal of $\mathrm{Cu}(\mathrm{II})$ ions, using the pseudo-first-order, pseudo-second-order, and intraparticle diffusion models; the dosage used was $0.5 \mathrm{~g} \cdot \mathrm{L}^{-1}$. Figure 6 shows the evolution of the removal capacity with time, while Table 3 shows the respective apparent rate constants for each tested model.

Table 3. Kinetic parameters of copper removal from aqueous solutions onto synthetic zeolites.

\begin{tabular}{|c|c|c|c|c|c|c|c|c|c|c|}
\hline \multirow[b]{2}{*}{${ }^{a} \mathrm{NZ}$} & \multirow{2}{*}{$\begin{array}{c}\mathrm{b}^{\mathrm{b}} \text { Experimental } \\
\mathrm{q}_{\mathrm{e}, \exp } \\
\mathrm{mg} \cdot \mathrm{g}^{-1}\end{array}$} & \multicolumn{3}{|c|}{ Pseudo-First-Order } & \multicolumn{3}{|c|}{ Pseudo-Second-Order } & \multicolumn{3}{|c|}{ Intraparticle Diffusion } \\
\hline & & $\underset{\mathrm{mg}, \mathrm{cal}}{\mathrm{q}^{-1}}$ & $\begin{array}{c}\mathrm{k}_{1} \\
\min ^{-1}\end{array}$ & $\mathbf{R}^{2}$ & $\underset{\mathrm{mg} \cdot \mathrm{g}^{-1}}{\mathrm{q}_{\mathrm{e}}}$ & $\stackrel{\mathrm{k}_{2}}{\mathrm{~g} \cdot \mathrm{mg}^{-1} \cdot \mathrm{min}^{-1}}$ & $\mathbf{R}^{2}$ & $\underset{\mathrm{mg} \cdot \mathrm{g}^{-1} \cdot \min ^{-0.5}}{\mathrm{k}_{\mathrm{p}}}$ & $\begin{array}{c}\mathrm{C} \\
\mathrm{mg} \cdot \mathrm{g}^{-1}\end{array}$ & $\mathbf{R}^{2}$ \\
\hline \multirow{4}{*}{$\mathrm{Z} 1$} & 93.49 & 10.72 & 0.260 & 0.721 & 93.54 & 0.3516 & 1.000 & 92.34 & 0.81 & 0.625 \\
\hline & 196.41 & 158.74 & 0.160 & 0.905 & 201.21 & 0.0034 & 0.997 & 93.30 & 21.12 & 0.936 \\
\hline & 258.69 & 204.87 & 0.117 & 0.930 & 265.96 & 0.0017 & 0.995 & 136.20 & 21.63 & 0.990 \\
\hline & 309.70 & 202.44 & 0.075 & 0.878 & 318.47 & 0.0011 & 0.994 & 145.95 & 26.33 & 0.951 \\
\hline \multirow{4}{*}{$\mathrm{Z} 1.5$} & 90.08 & 31.43 & 0.260 & 0.918 & 90.33 & 0.0756 & 0.999 & 3.91 & 75.38 & 0.698 \\
\hline & 176.54 & 95.52 & 0.201 & 0.929 & 177.94 & 0.0122 & 0.999 & 10.14 & 131.5 & 0.975 \\
\hline & 290.79 & 255.81 & 0.108 & 0.946 & 302.11 & 0.0011 & 0.991 & 23.75 & 132.7 & 0.838 \\
\hline & 294.01 & 206.82 & 0.089 & 0.847 & 305.81 & 0.0011 & 0.991 & 29.03 & 135.9 & 0.722 \\
\hline
\end{tabular}

${ }^{a} \mathrm{NZ}$, Na zeolites; Z1 and Z1.5, ZFA1Na and ZFA1.5Na, respectively; ${ }^{\mathrm{b}}$ dosage, $0.5 \mathrm{~g} \cdot \mathrm{L}^{-1} ; 25^{\circ} \mathrm{C}$; stirring speed, 600 rpm; time, $60 \mathrm{~min}$. 


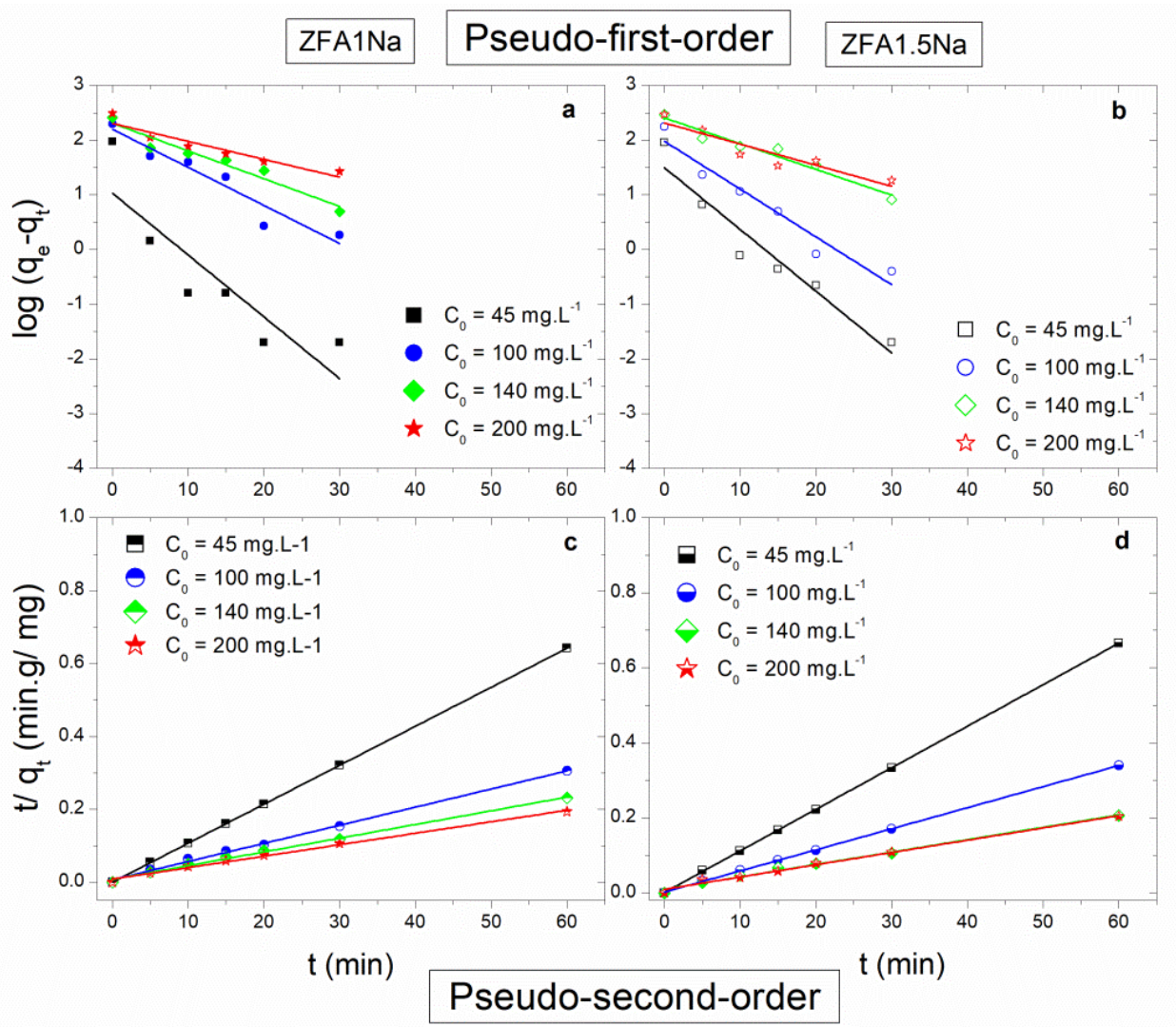

Figure 6. Pseudo-first-order $(\mathbf{a}, \mathbf{b})$ and pseudo-second-order $(\mathbf{c}, \mathbf{d})$ removal of $\mathrm{Cu}$ onto ZFA1Na and ZFA1.5Na zeolites (dosage $0.5 \mathrm{~g} \cdot \mathrm{L}^{-1}, \mathrm{Cu}$ concentration $45-200 \mathrm{mg} \mathrm{L}^{-1}$ ).

It was seen from the data that the pseudo-second-order model fits $\left(R^{2}\right.$ values, $\left.0.991-1\right)$ the experimental data very well for both the zeolites used, indicating that the reaction rate depended on the number of available active sites on the surface $[32,49,50]$. For the initial $\mathrm{Cu}(\mathrm{II})$ ion concentrations of 45 and $100 \mathrm{mg} \cdot \mathrm{L}^{-1}$, the removal capacity of ZFA1Na was 93 and $196 \mathrm{mg} \cdot \mathrm{g}^{-1}$, respectively; this capacity was significantly higher compared with the capacity $\left(40-70 \mathrm{mg} \cdot \mathrm{g}^{-1}\right)$ calculated in an earlier study in which the removal of multiple metal ions, namely, $\mathrm{Co}(\mathrm{II}), \mathrm{Cr}(\mathrm{III}), \mathrm{Ni}(\mathrm{II}), \mathrm{Zn}(\mathrm{II})$, and $\mathrm{Cu}(\mathrm{II})$, was investigated with the use of zeolites [29]. The calculated removal capacity, $\mathrm{q}_{\mathrm{e}, \mathrm{cal}}$ agreed well with the experimental removal capacity, $\mathrm{q}_{\mathrm{e}, \text { exp }}$; the maximum difference was $4 \%$. The apparent rate constant, $\mathrm{k}_{2}$, varied for different initial concentrations of $\mathrm{Cu}$ (II) ions, especially for the smaller ones.

It was noted that the removal capacity $\left(\mathrm{q}_{\mathrm{e}, \mathrm{cal}}\right)$ increased with an increase in the initial copper concentrations and seemed to stabilize at the higher initial $\mathrm{Cu}(\mathrm{II})$ ion concentrations tested, 140 and $200 \mathrm{mg} \mathrm{L}^{-1}$. These results were consistent with previous studies [51,52]. The kinetics of $\mathrm{Cu}$ (II) removal on coal ash-derived zeolite was also described by the pseudo-second-order model [53] and showed higher equilibrium time $\left(>50 \mathrm{~h}\right.$ at 30 and $\left.40^{\circ} \mathrm{C}\right)$ compared with the present study $(<1 \mathrm{~h})$.

The pseudo-second-order kinetic model is based on the assumption that the chemisorption is the rate-determining step [54]. However, the removal mechanism cannot be based on simple fitting of the pseudo-second-order model [55]. Both pseudo-first-order and pseudo-second-order models did not explain the diffusion of the solute into the material; therefore, before any conclusions were drawn about the mechanism, the intraparticle diffusion model was also investigated. According to this model, the nature of the rate-controlling step is predicted by taking into account surface and/or pore diffusion. The resulting straight lines did not cross the origin (Figure 7) and therefore, intraparticle diffusion was not the only rate-limiting step. However, the nonlinearity of copper data indicated that more than one process was involved in copper removal. In particular, the first sharp relation (first linear fit) was attributed to copper diffusion from the solution to the external surface of synthetic zeolites 
(external diffusion), whereas the second relation (second linear fit) revealed progressive ion diffusion inside the pores (intraparticle diffusion). The kinetic data indicated that the mechanism of copper ion removal from aqueous solutions was complex and probably involved a combination of chemisorption and intraparticle diffusion through the surface/pores of synthetic zeolites. This finding was in line with previous kinetic studies involving heavy metal uptake from synthetic zeolites [56,57].
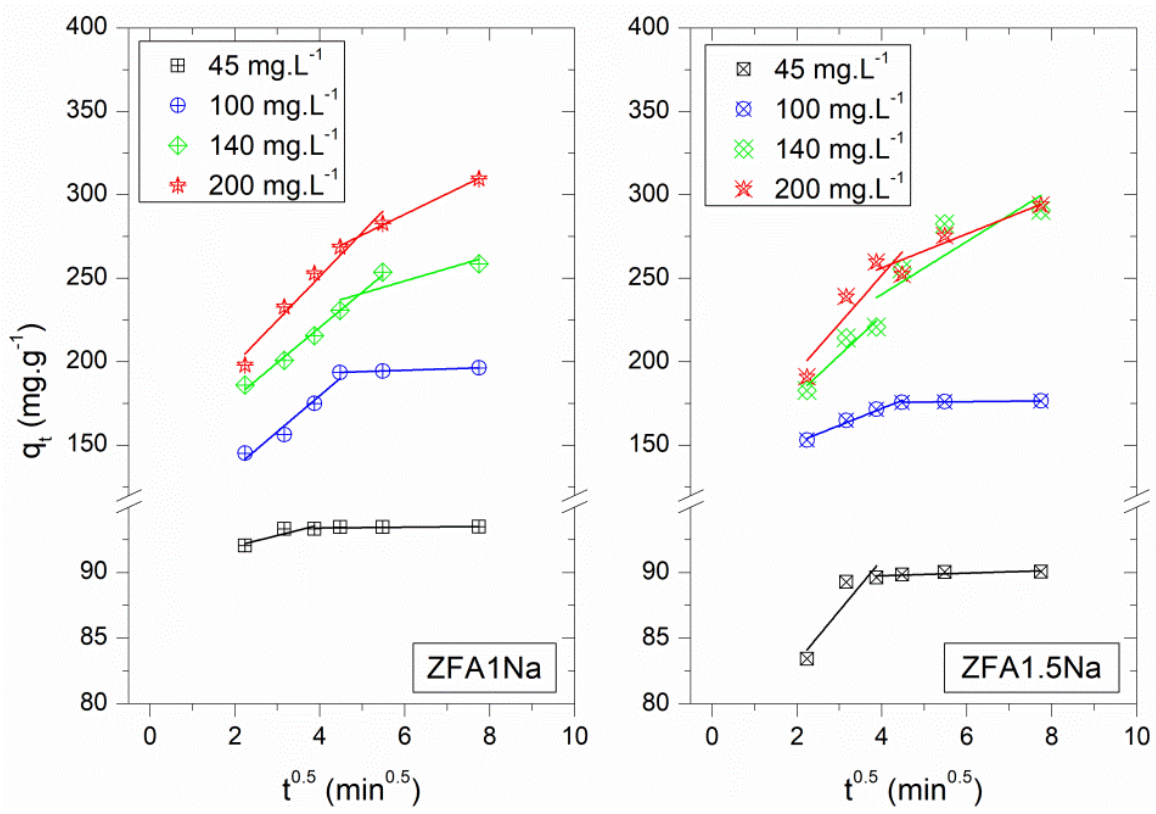

Figure 7. Intraparticle diffusion model for copper removal onto ZFA1Na and ZFA1.5Na zeolites.

Table 4 presents the results of previous studies pertinent to the removal of $\mathrm{Cu}$ (II) ions on zeolites produced from lignite fly ash and other materials and compares them with the results of the present study. The low removal capacity of natural zeolite $\left(1 \mathrm{mg} \cdot \mathrm{g}^{-1}\right.$ for $\mathrm{Cu}$ (II)) was evaluated for $\mathrm{Cu}$ (II) aqueous solutions when a very high dosage $\left(37 \mathrm{~g} \cdot \mathrm{L}^{-1}\right)$ was used [58]. The removal capacity of fly ash-derived zeolites, namely, zeolite types $\mathrm{A}$ and $\mathrm{X}$ and coal ash-based zeolites [31,42], were lower compared with that in our study even when a high dosage $\left(5 \mathrm{~g} \cdot \mathrm{L}^{-1}\right)$ was used. Pyrolyzed pistachio shells (biochar) can also be effectively used for the removal of $\mathrm{Cu}$ (II) [57]. In the present study, the removal capacity of raw FA was also determined and found to be $38 \mathrm{mg} \cdot \mathrm{g}^{-1}$. However, the removal capacity of ZFA1Na was higher $\left(q_{\mathrm{e}}, \sim 310 \mathrm{mg} \cdot \mathrm{g}^{-1}\right)$ compared with that observed for all other studies when a low dosage $\left(0.5 \mathrm{~g} \cdot \mathrm{L}^{-1}\right)$ was used.

Table 4. Data on $\mathrm{Cu}(\mathrm{II})$ and $\mathrm{Zn}(\mathrm{II})$ (initial concentration values) removal by zeolite-type materials.

\begin{tabular}{ccccccccc}
\hline $\begin{array}{c}\text { Materials Used for } \\
\text { Copper Removal }\end{array}$ & $\begin{array}{c}\mathbf{C u ( I I )} \\
\begin{array}{c}\text { Concentration } \\
\mathbf{m g} \cdot \mathbf{L}^{-\mathbf{1}}\end{array}\end{array}$ & $\mathbf{p H}$ & $\begin{array}{c}\mathbf{T} \\
{ }^{\mathbf{C}} \mathbf{C}\end{array}$ & $\begin{array}{c}\text { Time } \\
\mathbf{h}\end{array}$ & $\begin{array}{c}\text { Dosage } \\
\mathbf{g} \cdot \mathbf{L}^{-\mathbf{1}}\end{array}$ & $\begin{array}{c}\text { Removal } \\
\text { Capacity } \\
\mathbf{m g} \cdot \mathbf{g}^{\mathbf{- 1}}\end{array}$ & $\begin{array}{c}\text { Removal } \\
\text { Degree } \\
\%\end{array}$ & Reference \\
\hline Natural zeolite (clinoptilolite) & 20 & 3.5 & 22 & 6 & 37 & 0.54 & 98 & {$[58]$} \\
Zeolite A & 200 & 3 & 25 & 4 & 5 & 38 & & {$[42]$} \\
Zeolite X & 200 & 3 & 25 & 4 & 5 & 29 & & {$[31]$} \\
Zeolite 4A (from coal fly ash) & 100 & $3-4$ & 25 & 4 & 1 & $20-70$ & $20-80$ & {$[59]$} \\
Pistachio shell biochar & 150 & $7.15 *$ & 25 & 24 & 10 & 9.5 & 63 & Present study \\
ZFA1Na & 200 & 5.5 & 25 & 1 & 0.5 & 310 & 80 & \\
\hline
\end{tabular}

* The $\mathrm{pH}$ was measured in the aqueous solution containing biochar produced at $550{ }^{\circ} \mathrm{C}$.

\subsection{Morphology and Composition Analysis of Zeolites}

Based on the SEM/EDS analysis, the morphology of selected synthetic zeolites (ZFA1Na and ZFA1K) prior to and after copper removal is shown in Figure 8a,c. Due to their inherent characteristics, raw FA mostly presented a smooth spherical surface consisting of solid ash particles and cenospheres 
(image not shown). On the other hand, both zeolite surfaces turned from smooth in the FA to rugged, due to the formation of new zeolite crystal clusters as a result of alkaline fusion. The synthetic zeolite ZFA1Na presented an angular-like structure consisting of cubic crystals with an almost constant size $(\sim 15 \mu \mathrm{m})$, typical for A-type zeolite [60], which was confirmed by XRD results. However, the synthetic zeolite ZFA1K exhibited higher heterogeneity both in size and shape compared with ZFA1Na. In this case, prism-like clusters of varying sizes (up to $22 \mu \mathrm{m}$ ) and irregular shapes were formed onto the synthetic zeolite particles, typical for Linde F-type zeolite [40] and in accordance with XRD results.

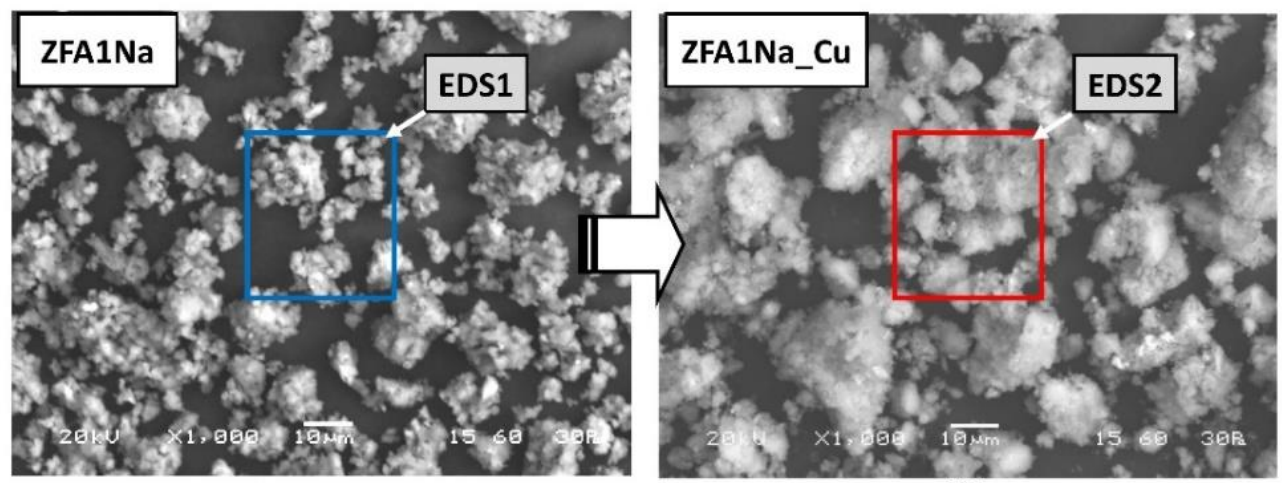

(a)

(b)

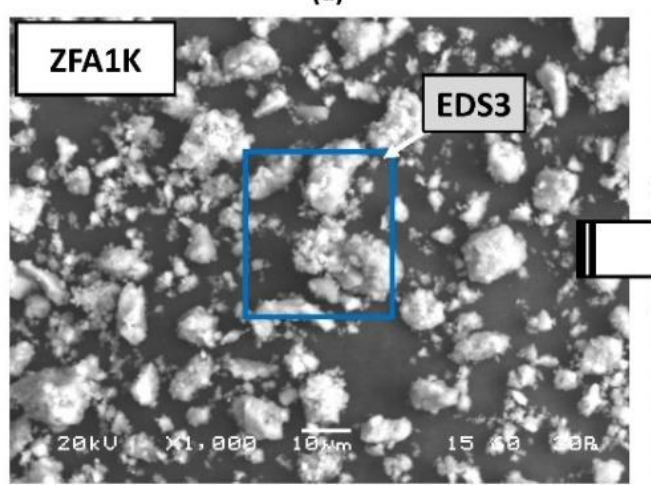

(c)

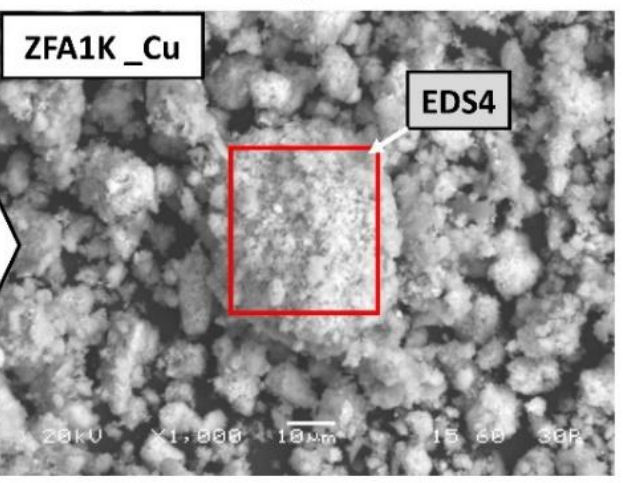

(d)

Figure 8. Comparison of morphology obtained for synthetic zeolites ZFA1Na and ZFA1K based on SEM/EDS analyses prior to ((a) ZFA1Na and (c) and ZFA1K) and after removal ((b) ZFA1Na_Cu and (d) ZFA1K_Cu) of $\mathrm{Cu}(\mathrm{II})$ ions. Concentration, $200 \mathrm{mg} \cdot \mathrm{L}^{-1}$; zeolite dosage, $0.5 \mathrm{~g} \cdot \mathrm{L}^{-1}$. EDS analyses were performed on the square highlighted regions (1-4).

After copper removal, the morphology of ZFA1Na_Cu (Figure 8b) and ZFA1K_Cu (Figure 8d) changed significantly and exhibited a more crystalline structure with greater degree of agglomeration and uniformity. EDS analyses carried out on representative regions (blue squares) of the zeolites ZFA1Na and ZFA1K showed that their semi-quantitative elemental composition corresponded to Ca, $\mathrm{Al}, \mathrm{Fe}$, and $\mathrm{Si}$ along with the higher intensity of $\mathrm{Na}$ and/or $\mathrm{K}$, depending on the fluxing agents used, i.e., $\mathrm{NaOH}$ or $\mathrm{KOH}$ (spectra a and c of Figure 9, respectively). After removal, EDS spectra corresponding to red square regions (EDS2 and EDS4) clearly confirmed the presence of copper on the surfaces of the synthetic zeolites (ZFA1Na and ZFA1K), as shown in spectra b and d of Figure 9, respectively.

Copper was detected by SEM/EDS analyses on both the synthetic zeolites, ZFA1Na_Cu and ZFA1K_Cu, revealing that $\mathrm{Cu}(\mathrm{II})$ ions were removed from aqueous solutions. In both the cases, the disappearance of $\mathrm{Ca}, \mathrm{Mg}, \mathrm{K}$, and $\mathrm{Na}$ may indicate their contribution to ion-exchange reactions involving $\mathrm{Cu}(\mathrm{II})$ ions [61]. Cations within the zeolite channels are free to move and are prone to diffuse into the bulk solution phase during experiments [62]. On the other hand, the appearance of $\mathrm{Cl}$ on the surface of both the zeolites (atomic percentage (at. \%), 7-10) was the result of the use of $0.1 \mathrm{M} \mathrm{NaCl}$ for the preparation of aqueous solutions with a constant ionic strength. 

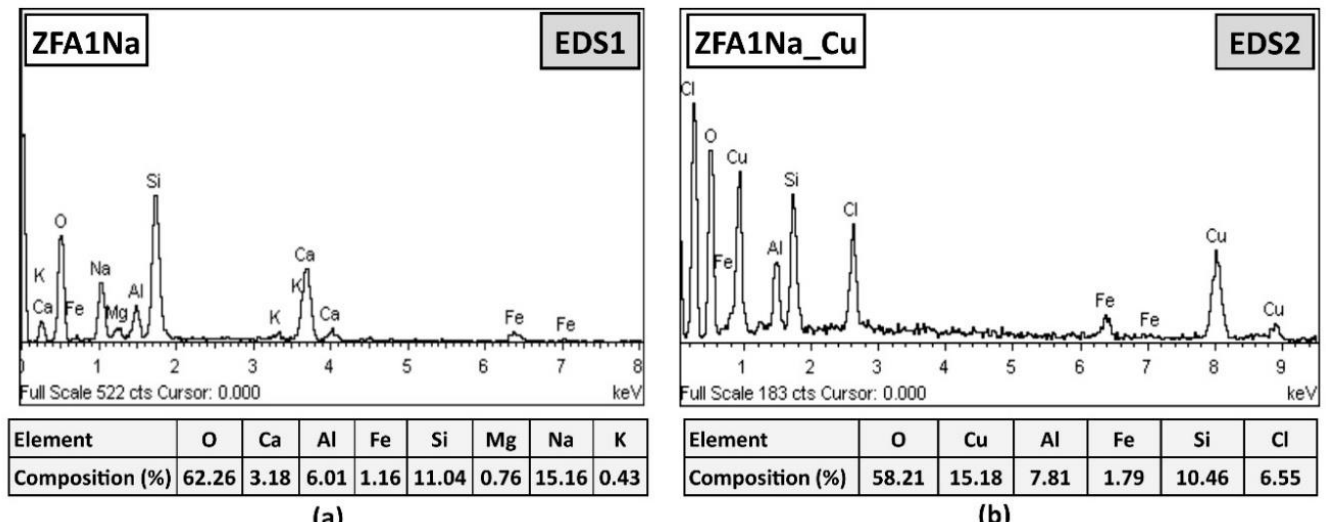

(b)

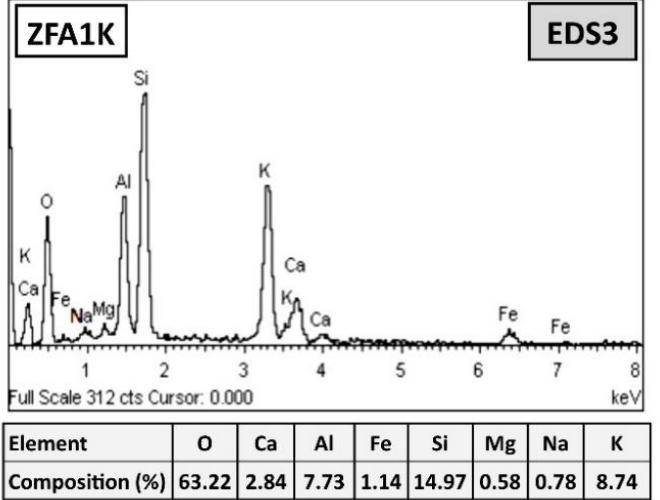

(c)

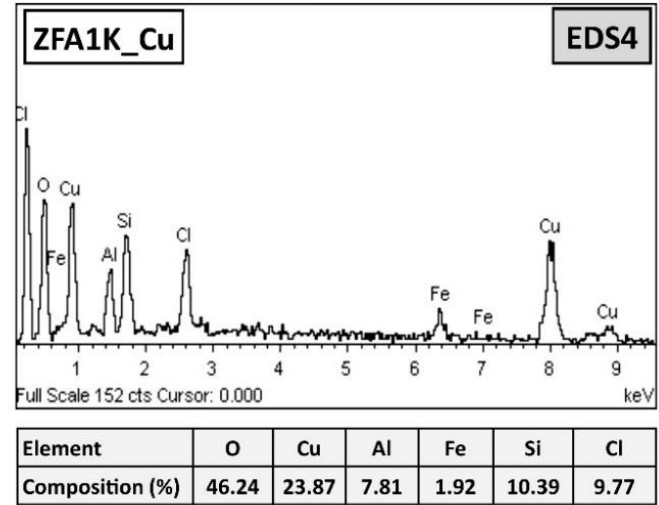

(d)

Figure 9. EDS spectra and elemental composition in terms of atomic percentage (at. \%) of the synthetic zeolites prior to ((a) ZFA1Na and (c) and ZFA1K) and after removal ((b) ZFA1Na_Cu and (d) ZFA1K_Cu) of $\mathrm{Cu}(\mathrm{II})$ ions, respectively (shown as square regions in Figure 3). Initial $\mathrm{Cu}$ ion concentration, $200 \mathrm{mg} \cdot \mathrm{L}^{-1}$; zeolite dosage, $0.5 \mathrm{~g} \cdot \mathrm{L}^{-1}$.

\subsection{Copper Chemical State by XPS Analysis}

The chemical state of $\mathrm{Cu}$ and the relative atomic concentration of the zeolite's surface was investigated by means of XPS spectroscopy. XRS was performed in the synthetic zeolite before (ZFA1Na) and after (ZFA1Na_Cu) copper removal (initial copper concentration, $200 \mathrm{mg} \cdot \mathrm{L}^{-1}$; zeolite dosage, $0.5 \mathrm{~g} \cdot \mathrm{L}^{-1}$ ). In the XPS survey scans (Figure 10) of the synthetic zeolite before and after copper removal, $\mathrm{Al}, \mathrm{Si}, \mathrm{O}, \mathrm{Na}$, and $\mathrm{Cl}$ peaks were present on both the surfaces, whereas intense Na peaks were present on the ZFA1Na surface and $\mathrm{Cu}$ prevailed on ZFA1Na_Cu. Moreover, Ca peaks were present in the ZFA1Na sample, whereas in the ZFA1Na_Cu sample, the peak overlapped with the CuLVV (L-shell valence valence) Auger peaks. The detailed Cu2p, Si2p, and the combined Al2p-Cu3p XPS core level spectra of both samples are provided as Supplementary Material (Figure S2).

From the peak area of Cu2p3/2, Si2p, Al2p, Na1s, and Cl2p, the atomic concentration (At, \%) can be calculated at appointed binding energies (Table 5). The binding energy of Cu2p3/2 of ZFA1Na_Cu sample at $934.3 \mathrm{eV}$ and a high copper atomic concentration $(26.8 \%)$ was measured for the synthetic zeolite after copper removal. The $\mathrm{Cu} 2 \mathrm{p}$ peak shape with the intense satellites proved that $\mathrm{Cu}(\mathrm{II})$ ions were present on the synthetic surface (within $10 \mathrm{~nm}$ depth according to XPS analysis limitations) in small cages as well as in open channels of the zeolite.

In order to identify the chemical state of $\mathrm{Cu}$, the CuLVV spectrum (X-ray-induced Auger electron spectroscopy) was recorded (not shown); and the Cu-modified Auger parameter, $\alpha$, (derived from the sum of the Cu2p3/2 binding energy and the CuL3VV kinetic energy) was $1851.6 \mathrm{eV}$. Chen et al. [63] suggested the presence of $\mathrm{Cu}(\mathrm{II})$ ion species as a $\mathrm{CuO}$ cluster at $933.7 \mathrm{eV}$ inside the zeolite pore structure. They supported that, due to low hydration energy, $\mathrm{Cu}$ ions can lose part of their water of hydration. The partially hydrated $\mathrm{Cu}$ ions are small enough to enter the zeolite channels, giving rise to 
$\mathrm{Cu}$-distribution ions through the synthetic zeolite surface. According to Biesinger et al. [64], the binding energy of $\mathrm{Cu} 2 \mathrm{p} 3 / 2$ for $\mathrm{CuO}$ assigned to $\mathrm{Cu}$ (II) species was at $933.6 \mathrm{eV}$, whereas for $\mathrm{Cu}(\mathrm{OH})_{2}$, it was at $934.8 \mathrm{eV}$. On the contrary, the Auger parameter was $1851.4 \pm 0.1 \mathrm{eV}$ for both $\mathrm{CuO}$ and $\mathrm{Cu}(\mathrm{OH})_{2}$. Therefore, our results indicated that $\mathrm{CuO}$ and/or $\mathrm{Cu}(\mathrm{OH})_{2}$ were present in the zeolite. In addition, $\mathrm{Cl} 2 \mathrm{p}$ binding energy region showed a characteristic $\mathrm{Cl} 2 \mathrm{p} 3 / 2$ peak at $198.2 \mathrm{eV}$. This may be assigned to chlorine atoms as $\mathrm{Cu}-\mathrm{Cl}$, forming low amounts of atacamite [65].

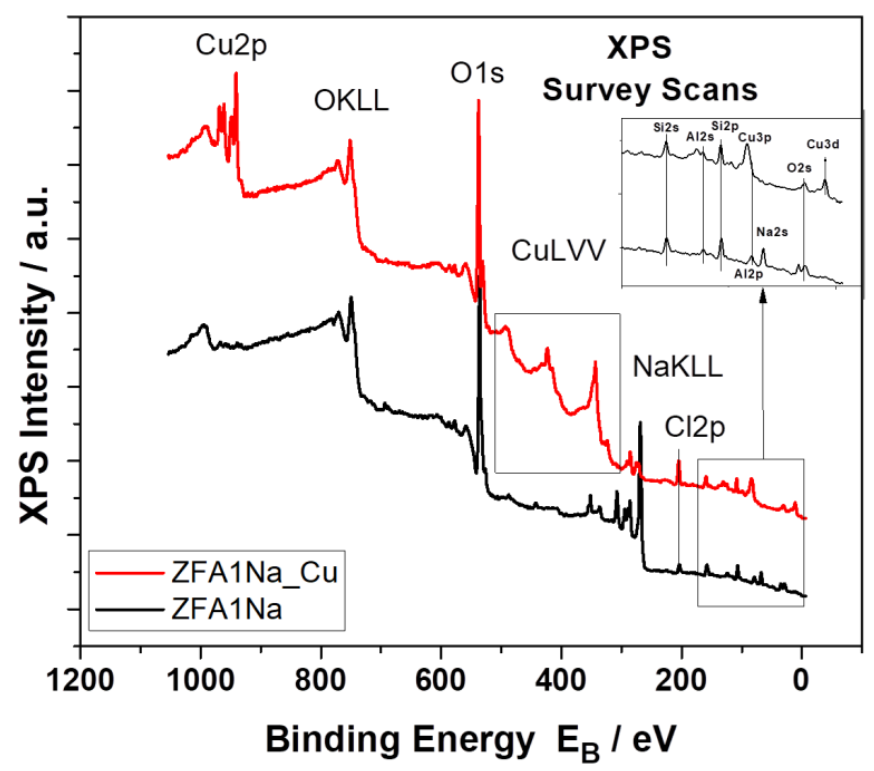

Figure 10. XPS survey scans of ZFA1Na and ZFA1Na_Cu samples.

Table 5. Surface atomic concentrations of main elements in zeolite before (ZFA1Na) and after copper removal (ZFA1Na_Cu). Comparison of surface atomic ratios derived from XPS with SEM/EDS.

\begin{tabular}{|c|c|c|c|}
\hline & & \multicolumn{2}{|c|}{ Sample No. } \\
\hline & & ${ }^{\text {a }} \mathrm{ZFA1Na}$ & ZFA1Na_Cu \\
\hline \multicolumn{4}{|c|}{ Surface analysis (XPS) } \\
\hline \multirow{2}{*}{$\mathrm{Cu} 2 \mathrm{p} 3 / 2$} & ${ }^{\mathrm{b}} \mathrm{Eb}(\mathrm{eV})$ & n.a. & 934.3 \\
\hline & ${ }^{\mathrm{c}}$ At $(\%)$ & n.a. & $26.8 \pm 0.3$ \\
\hline \multirow{2}{*}{$\mathrm{Si} 2 \mathrm{p}$} & $\mathrm{Eb}(\mathrm{eV})$ & 102.2 & 102.0 \\
\hline & At $(\%)$ & $19.6 \pm 0.3$ & $20.6 \pm 0.3$ \\
\hline \multirow{2}{*}{$\mathrm{Al} 2 \mathrm{p}$} & $\mathrm{Eb}(\mathrm{eV})$ & 73.9 & 73.7 \\
\hline & At $(\%)$ & $13.8 \pm 0.5$ & $20.1 \pm 0.7$ \\
\hline \multirow{2}{*}{ Na1s } & $\mathrm{Eb}(\mathrm{eV})$ & 1072.2 & 1072.5 \\
\hline & At $(\%)$ & $61.0 \pm 0.3$ & $19.2 \pm 0.3$ \\
\hline \multirow{2}{*}{$\mathrm{Cl} 2 \mathrm{p}$} & $\mathrm{Eb}(\mathrm{eV})$ & 198.2 & 198.2 \\
\hline & At $(\%)$ & $5.5 \pm 0.01$ & $13.1 \pm 0.3$ \\
\hline \multicolumn{2}{|c|}{$\mathrm{Cu} / \mathrm{Si}$} & n.a. & 1.3 \\
\hline \multicolumn{2}{|c|}{$\mathrm{Si} / \mathrm{Al}$} & 1.4 & 1.0 \\
\hline \multicolumn{2}{|c|}{$\mathrm{Na} / \mathrm{Si}$} & 3.1 & 0.9 \\
\hline \multicolumn{2}{|c|}{$\mathrm{Cl} / \mathrm{Si}$} & 0.3 & 0.6 \\
\hline \multicolumn{4}{|c|}{ Bulk analysis (SEM/EDS) } \\
\hline \multicolumn{2}{|c|}{$\mathrm{Cu} / \mathrm{Si}$} & n.a. & 1.5 \\
\hline \multicolumn{2}{|c|}{$\mathrm{Si} / \mathrm{Al}$} & 1.8 & 1.3 \\
\hline
\end{tabular}

a Abbreviations: Fly ash-derived zeolite (ZFA1Na) and after removal of copper solution (ZFA1Na_Cu); initial Cu ion concentration, $200 \mathrm{mg} \cdot \mathrm{L}^{-1}$; dosage, $0.5 \mathrm{~g} . \mathrm{L}^{-1} ; \mathrm{NaCl}, 0.1 \mathrm{M} .{ }^{\mathrm{b}} \mathrm{Eb}$, binding energy $(\mathrm{eV}) ;{ }^{\mathrm{c}}$ (At, \%) atomic concentration; n.a., not applicable. 
The atomic concentration of $\mathrm{Si}$ on the zeolite surface was relatively increased compared with that of the synthetic zeolite and the atomic concentration of Al was increased from $13.8 \%$ to $20.1 \%$ with a broader spectrum after copper removal. A decrease in Na loading from $61.0 \%$ to $19.2 \%$ was defined, implying that $\mathrm{Na}$ may be involved as an exchangeable cation in the uptake of $\mathrm{Cu}$. Despite the presence of $\mathrm{NaCl}$ in solution, the XPS analysis revealed that potentially available $\mathrm{Na}$ ions from $\mathrm{NaCl}$ did not interact with the surface during the process. However, $\mathrm{Na}$ and $\mathrm{Cl}$ ions initially present in the synthetic zeolite may contribute to the copper removal process.

The comparison of $\mathrm{Cu} / \mathrm{Si}, \mathrm{Si} / \mathrm{Al}$ and $\mathrm{Na} / \mathrm{Si}$ atomic ratios on the surface for the synthetic zeolite (before and after copper removal) was calculated. The $\mathrm{Cu} / \mathrm{Si}$ ratio increased, indicating the presence of copper on the synthetic zeolite surface after copper removal from aqueous solutions. Both $\mathrm{Si} / \mathrm{Al}$ and $\mathrm{Na} / \mathrm{Si}$ atomic ratios decreased from 1.4 to 1.0 and from 3.1 to 0.9 , respectively. The $\mathrm{Cu} / \mathrm{Si}$ ratio after EDS analysis was higher compared with that after XPS analysis, due to higher copper content in the bulk compared with surface analysis (XPS). XPS measurements are bound to the limited penetration depth of a few nanometers (i.e., $<10 \mathrm{~nm}$ ) from the surface as well as to the dependence on the distribution of copper species. Therefore, copper content measured by XPS can become an indicator to which extent $\mathrm{Cu}$ is inserted into the zeolitic channels when comparing the results with the EDS measurements that probe the bulk composition of the samples. However, XPS analysis data correlated well with that of $\mathrm{SEM} / \mathrm{EDS}$ analyses considering $\mathrm{Si} / \mathrm{Al}$ atomic ratios. The coincidence of $\mathrm{Si} / \mathrm{Al}$ ratio measurements from XPS and bulk analysis was often determined [66].

No shift in binding energy of appointed components was monitored, thus no new chemical bonding was observed. Differences in $\mathrm{Si} / \mathrm{Al}, \mathrm{Na} / \mathrm{Si}$, and $\mathrm{Cu} / \mathrm{Si}$ ratios may reveal the migration of ions from the bulk to the surface [66], thus indicating diffusion as a possible removal mechanism among aqueous copper ions and $\mathrm{Na}$ ions initially present in synthetic zeolites. The XPS spectra analysis may explain the removal mechanism in cases where various interactions between surface active sites (functional groups) and metal ions occur [67]. Kim et al. [35] studied iron-incorporated A-type zeolite, revealing a decrease in $\mathrm{Si} / \mathrm{Al}$ and $\mathrm{Na} / \mathrm{Si}$ ratios after XPS analysis. A surface composition analysis of natural zeolites before and after heavy metal uptake showed a decrease in $\mathrm{Na} / \mathrm{Si}$ ratio, whereas the $\mathrm{Si} / \mathrm{Al}$ ratio was constant [34]. In this study, the Si/Al atomic ratio for the synthetic zeolite after copper removal was close to 1, demonstrating A-type zeolite. Zeolite A has the framework composition with a high $\mathrm{Al}$ content and an $\mathrm{Si} / \mathrm{Al}$ molar ratio of almost 1 . In tetrahedral aluminosilicate frameworks, this is the highest $\mathrm{Al}$ content [68]. In zeolite A, the Al-framework is balanced by the maximum number of cation-exchange sites; it has a high cation content and superior exchange capacity and potentially may have applications for ion-exchange in industrial processes [69].

\section{Conclusions}

Greek lignite fly ash was efficiently converted into zeolites through alkaline fusion with the use of $\mathrm{NaOH}$ and $\mathrm{KOH}$. Mineralogical analyses revealed the presence of zeolite A, zeolite X, and sodalite on the zeolites obtained after $\mathrm{NaOH}$ fusion and Linde F-type zeolite after $\mathrm{KOH}$ fusion. Screening tests involving the removal of $\mathrm{Cu}(\mathrm{II})$ ions indicated that $\mathrm{Na}$ zeolites exhibited higher copper removal efficiency compared with $\mathrm{K}$ zeolites.

The removal capacity of $\mathrm{Na}$ zeolites for $\mathrm{Cu}$ (II) ions depended mainly on the initial $\mathrm{Cu}$ (II) ion concentration present in the aqueous solution. The removal capacity obtained for $\mathrm{Cu}$ (II) ions in the present study was very high and reached 310 and $294 \mathrm{mg} \cdot \mathrm{g}^{-1}$ for ZFA1Na and ZFA1.5Na zeolites, respectively. The removal kinetics were quite fast within the first $30 \mathrm{~min}$, indicating that $\sim 70 \%$ of $\mathrm{Cu}(\mathrm{II})$ ions, at the initial metal concentration of $200 \mathrm{mg} \cdot \mathrm{L}^{-1}$, were removed from the solution. The pseudo-second-order kinetic model fit the experimental data very well. SEM/EDS analyses proved the presence of copper in the zeolitic framework including open channels and the presence of $\mathrm{Cu}$ (II) oxidation state possibly due to the formation of $\mathrm{CuO}$ and/or $\mathrm{Cu}-\mathrm{Cl}$ according to XPS analysis.

In conclusion, the present study proved that synthetic zeolites can be produced from lignite fly ash and can be used as efficient materials for the decontamination of industrial wastewaters containing 
high amounts of $\mathrm{Cu}(\mathrm{II})$ ions. This approach can result in the valorization of industrial wastes and the elimination of environmental problems caused by their improper disposal mainly at lignite mining centers and combustion stations.

Supplementary Materials: The following are available online at http://www.mdpi.com/2075-163X/10/10/844/s1, Figure S1: Calculation of saturation indices (SI) at different $\mathrm{pH}(2-10)$ with respect to atacamite $\left(\mathrm{Cu}_{2}(\mathrm{OH})_{3} \mathrm{Cl}\right)$, $\mathrm{CuO}, \mathrm{Cu}(\mathrm{OH})_{2}$, and $\mathrm{Cu}_{2}(\mathrm{OH})_{3} \mathrm{NO}_{3}$ using PHREEQC code v.3.4.0 and minteq.v4 database. Figure S2: XPS core level spectra of $\mathrm{Cu} 2 \mathrm{p}, \mathrm{Si} 2 \mathrm{p}$, and a combined $\mathrm{Al} 2 \mathrm{p}-\mathrm{Cu} 3 \mathrm{p}$ region of ZFA1Na (a) before and (b) after copper removal (ZFA1Na_Cu).

Author Contributions: A.V. carried out tests and analyses and wrote the first draft of the paper; G.B. interpreted data and carried out SEM/EDS analyses; K.K. designed the tests and critically reviewed results and the paper. All authors have read and agreed to the published version of the manuscript.

Funding: The research was carried out in the frame of the project "INVALOR: Research Infrastructure for Waste Valorization and Sustainable Management" (MIS 5002495), which is implemented under the Action "Reinforcement of the Research and Innovation Infrastructure", funded by the Operational Programme "Competitiveness, Entrepreneurship and Innovation" (NSRF 2014-2020) and co-financed by Greece and the European Union (European Regional Development Fund).

Acknowledgments: A.I. Vavouraki wishes to thank A. Stratakis (TUC) and L. Sygellou (Surface Science Laboratory, FORTH/ICE-HT) for performing XRD and XPS analysis, respectively.

Conflicts of Interest: The authors declare no conflict of interest. The funding organization had no role in the design of the study; in the collection, analyses, or interpretation of data; in the writing of the manuscript, and in the decision to publish the results.

\section{References}

1. Market Report Series: Coal 2019. Analysis and Forecasts to 2024. Available online: https://www.iea.org/ reports/coal-2019 (accessed on 17 September 2020).

2. Belviso, C. State-of-the-art applications of fly ash from coal and biomass: A focus on zeolite synthesis processes and issues. Prog. Energy Combust. Sci. 2018, 65, 109-135. [CrossRef]

3. Zaravelis, F.; Theodorakis, N.; Triantafyllou, A.; Stivanakis, V. Fly ash of Megalopolis and ferroalumina in the production of building materials. Mater. Today Proc. 2018, 5, 27434-27440. [CrossRef]

4. Jambhulkar, H.P.; Shaikh, S.M.S.; Kumar, M.S. Fly ash toxicity, emerging issues and possible implications for its exploitation in agriculture; Indian scenario: A review. Chemosphere 2018, 213, 333-344. [CrossRef]

5. Chousidis, N.; Rakanta, E.; Ioannou, I.; Batis, G. Mechanical properties and durability performance of reinforced concrete containing fly ash. Constr. Build. Mater. 2015, 101, 810-817. [CrossRef]

6. Savvilotidou, V.; Kritikaki, A.; Stratakis, A.; Komnitsas, K.; Gidarakos, E. Energy efficient production of glass-ceramics using photovoltaic (P/V) glass and lignite fly ash. Waste Manag. 2019, 90, 46-58. [CrossRef]

7. Komnitsas, K.; Zaharaki, D.; Perdikatsis, V. Geopolymerisation of low calcium ferronickel slags. J. Mater. Sci. 2006, 42, 3073-3082. [CrossRef]

8. Toniolo, N.; Boccaccini, A.R. Fly ash-based geopolymers containing added silicate waste. A review. Ceram. Int. 2017, 43, 14545-14551. [CrossRef]

9. Ram, L.; Masto, R. Fly ash for soil amelioration: A review on the influence of ash blending with inorganic and organic amendments. Earth Sci.Rev. 2014, 128, 52-74. [CrossRef]

10. Volli, V.; Purkait, M.K.; Shu, C.-M. Preparation and characterization of animal bone powder impregnated fly ash catalyst for transesterification. Sci. Total. Environ. 2019, 669, 314-321. [CrossRef]

11. Mushtaq, F.; Zahid, M.; Bhatti, I.A.; Nasir, S.; Hussain, T. Possible applications of coal fly ash in wastewater treatment. J. Environ. Manag. 2019, 240, 27-46. [CrossRef]

12. Chen, L.; Wang, L.; Cho, D.-W.; Tsang, D.C.; Tong, L.; Zhou, Y.; Yang, J.; Hu, Q.; Poon, C.S. Sustainable stabilization/solidification of municipal solid waste incinerator fly ash by incorporation of green materials.

J. Clean. Prod. 2019, 222, 335-343. [CrossRef]

13. Chaikittisilp, W.; Okubo, T. Zeolite and Zeolite-Like Materials. Handb. Solid State Chem. 2017, 7, 97-119. [CrossRef]

14. Koshy, N.; Singh, D.N. Fly ash zeolites for water treatment applications. J. Environ. Chem. Eng. 2016, 4, 1460-1472. [CrossRef]

15. Belviso, C.; Cavalcante, F.; Fiore, S. Synthesis of zeolite from Italian coal fly ash: Differences in crystallization temperature using seawater instead of distilled water. Waste Manag. 2010, 30, 839-847. [CrossRef] 
16. Franus, M.; Wdowin, M.; Bandura, L.; Franus, W. Removal of environmental pollutions using zeolites from fly ash: A review. Fres. Environ. Bull. 2015, 24, 854-866.

17. Asl, S.M.H.; Javadian, H.; Khavarpour, M.; Belviso, C.; Taghavi, M.; Maghsudi, M. Porous adsorbents derived from coal fly ash as cost-effective and environmentally-friendly sources of aluminosilicate for sequestration of aqueous and gaseous pollutants: A review. J. Clean. Prod. 2019, 208, 1131-1147. [CrossRef]

18. Itskos, G.; Koutsianos, A.; Koukouzas, N.; Vasilatos, C. Zeolite development from fly ash and utilization in lignite mine-water treatment. Int. J. Miner. Process. 2015, 139, 43-50. [CrossRef]

19. Moutsatsou, A.; Stamatakis, M.; Hatzitzotzia, K.; Protonotarios, V. The utilization of Ca-rich and Ca-Si-rich fly ashes in zeolites production. Fuel 2006, 85, 657-663. [CrossRef]

20. Ramírez, H.; Núñez, M.M.G.; Bogoya, A.B.; Gomez, D.F.B.; Ramos, C.; Di Luca, C.; Inchaurrondo, N.; Haure, P. Synthesis of coal fly ash zeolite for the catalytic wet peroxide oxidation of Orange II. Environ. Sci. Pollut. Res. 2018, 26, 4277-4287. [CrossRef]

21. Gupta, S.S.; Bhattacharyya, K.G. Adsorption of metal ions by clays and inorganic solids. RSC Adv. 2014, 4, 28537-28586. [CrossRef]

22. Megías-Sayago, C.; Lara-Ibeas, I.; Wang, Q.; Le Calvé, S.; Louis, B. Volatile organic compounds (VOCs) removal capacity of ZSM-5 zeolite adsorbents for near real-time BTEX detection. J. Environ. Chem. Eng. 2020, 8, 103724. [CrossRef]

23. Maiti, S.; Raj, H.; Bisht, R.; Minocha, A.K.; Panigrahi, S.K.; Alexander, S.J.; Singh, M. X-Ray photoelectron spectroscopy study on adsorption property of harmful air pollutants on zeolite prepared from fly ash. Mater. Res. Express 2018, 5, 085507. [CrossRef]

24. Tolentino, C.M.C.; De Luna, M.D.G.; Futalan, C.M.; Choi, A.E.S.; Manegdeg, F.G.; Grisdanurak, N. Influence of hydrocarbons on hydrogen chloride removal from refinery off-gas by zeolite NaY derived from rice husks. Sci. Total. Environ. 2020, 728, 138782. [CrossRef]

25. Lahori, A.H.; Mierzwa-Hersztek, M.; Demiraj, E.; Sajjad, R.U.; Ali, I.; Shehnaz, H.; Aziz, A.; Zuberi, M.H.; Pirzada, A.M.; Hassan, K.; et al. Direct and residual impacts of zeolite on the remediation of harmful elements in multiple contaminated soils using cabbage in rotation with corn. Chemosphere 2020, 250, 126317. [CrossRef]

26. Moraetis, D.; Papagiannidou, S.; Pratikakis, A.; Pentari, D.; Komnitsas, K. Effect of zeolite application on potassium release in sandy soils amended with municipal compost. Desalin. Water Treat. 2015, 57, 1-12. [CrossRef]

27. Wen, J.; Yi, Y.; Zeng, G. Effects of modified zeolite on the removal and stabilization of heavy metals in contaminated lake sediment using BCR sequential extraction. J. Environ. Manag. 2016, 178, 63-69. [CrossRef]

28. Zhao, H.; Huang, X.; Liu, F.; Hu, X.; Zhao, X.; Wang, L.; Gao, P.; Ji, P. A two-year field study of using a new material for remediation of cadmium contaminated paddy soil. Environ. Pollut. 2020, 263, 114614. [CrossRef]

29. Parkhurst, D.L.; Appelo, C. Description of Input and Examples for PHREEQC Version 3: A Computer Program for Speciation, Batch-Reaction, One-Dimensional Transport, and Inverse Geochemical Calculations. In Techniques and Methods; book 6; U.S. Geological Survey: Reston, VA, USA, 2013; 497p.

30. Komnitsas, K.; Bartzas, G.; Paspaliaris, I. Modeling of Reaction Front Progress in Fly Ash Permeable Reactive Barriers. Environ. Forensics 2006, 7, 219-231. [CrossRef]

31. Hui, K.S.; Chao, C.; Kot, S.; Chao, C.Y.H. Removal of mixed heavy metal ions in wastewater by zeolite 4A and residual products from recycled coal fly ash. J. Hazard. Mater. 2005, 127, 89-101. [CrossRef]

32. Komnitsas, K.; Zaharaki, D.; Bartzas, G.; Alevizos, G. Adsorption of Scandium and Neodymium on Biochar Derived after Low-Temperature Pyrolysis of Sawdust. Minerals 2017, 7, 200. [CrossRef]

33. Mthombeni, N.H.; Onyango, M.S.; Aoyi, O. Adsorption of hexavalent chromium onto magnetic natural zeolite-polymer composite. J. Taiwan Inst. Chem. Eng. 2015, 50, 242-251. [CrossRef]

34. Yuan, G.; Seyama, H.; Soma, M.; Theng, B.K.G.; Tanaka, A. Adsorption of some heavy metals by natural zeolites: XPS and batch studies. J. Environ. Sci. Health Part A 1999, 34, 625-648. [CrossRef]

35. Kim, K.S.; Park, J.O.; Nam, S.C. Synthesis of Iron-loaded Zeolites for Removal of Ammonium and Phosphate from Aqueous Solutions. Environ. Eng. Res. 2013, 18, 267-276. [CrossRef]

36. Gao, Y.; Ru, Y.; Zhou, L.; Wang, X.; Wang, J. Preparation and Characterization of Chitosan-Zeolite Molecular Sieve Composite for Ammonia and Nitrate Removal. Adv. Compos. Lett. 2018, 27, 185-192. [CrossRef]

37. Sygellou, L. An in-situ photoelectron spectroscopy study of the thermal processing of ammonium tetrathiomolybdate, (NH4)2MoS4, precursor. Appl. Surf. Sci. 2019, 476, 1079-1085. [CrossRef] 
38. ASTM C618: Standard Specification for Coal Fly Ash and Raw or Calcined Natural Pozzolan for Use in Concrete. Designation: C618-12a. Available online: http://materialstandard.com/wp-content/uploads/2019/ 08/C618-12a.pdf. (accessed on 23 September 2020).

39. Medina, A.R.; Gamero, P.M.; Almanz, J.M.R.; Cortés, D.A.H.; Vargas, G. Study of the zeolitization process of fly ash using an orthogonal array of taguchi experimental design. J. Chil. Chem. Soc. 2009, 54, $244-251$. [CrossRef]

40. Miyaji, F.; Murakami, T.; Suyama, Y. Formation of linde F zeolite by KOH treatment of coal fly ash. J. Ceram. Soc. Jpn. 2009, 117, 619-622. [CrossRef]

41. Querol, X.; Moreno, N.; Umaña, J.; Alastuey, A.; Hernández, E.; Lopez-Soler, A.; Plana, F. Synthesis of zeolites from coal fly ash: An overview. Int. J. Coal Geol. 2002, 50, 413-423. [CrossRef]

42. Wang, C.; Li, J.; Sun, X.; Wang, L.; Sun, X. Evaluation of zeolites synthesized from fly ash as potential adsorbents for wastewater containing heavy metals. J. Environ. Sci. 2009, 21, 127-136. [CrossRef]

43. Mainganye, D.; Ojumu, T.; Petrik, L. Synthesis of Zeolites Na-P1 from South African Coal Fly Ash: Effect of Impeller Design and Agitation. Materials 2013, 6, 2074-2089. [CrossRef]

44. Wang, P.; Sun, Q.; Zhang, Y.; Cao, J. Synthesis of Zeolite 4A from Kaolin and Its Adsorption Equilibrium of Carbon Dioxide. Materials 2019, 12, 1536. [CrossRef] [PubMed]

45. Azizli, K.; Rahi, R.A.; Man, Z.; Rahmiati, T.; Nuruddin, M. Effect of Sodium Hydroxide Concentration on the Mechanical Property of Non Sodium Silicate Fly Ash Based Geopolymer. J. Appl. Sci. 2014, 14, 3381-3384. [CrossRef]

46. Orha, C.; Pop, A.; Lazau, C.; Sfîrloagă, P.; Grozescu, I.; Tiponuţ, V.; Manea, F. Structural and Sorption Properties of Copper Doped Natural and Synthetic Zeolite. In Proceedings of the CAS 2011 Proceedings (2011 International Semiconductor Conference), Sinaia, Romania, 17-19 October 2011.

47. Tansel, B.; Sager, J.; Rector, T.; Garland, J.; Strayer, R.F.; Levine, L.; Roberts, M.; Hummerick, M.; Bauer, J. Significance of hydrated radius and hydration shells on ionic permeability during nanofiltration in dead end and cross flow modes. Sep. Purif. Technol. 2006, 51, 40-47. [CrossRef]

48. Munthali, M.W.; Johan, E.; Matsue, N. Proton Adsorption Selectivity of Zeolites in Aqueous Media: Effect of Exchangeable Cation Species of Zeolites. Environments 2015, 2, 91-104. [CrossRef]

49. Liu, Y. New insights into pseudo-second-order kinetic equation for adsorption. Colloids Surf. A Physicochem. Eng. Asp. 2008, 320, 275-278. [CrossRef]

50. Wang, J.; Guo, X. Adsorption kinetic models: Physical meanings, applications, and solving methods. J. Hazard. Mater. 2020, 390, 122156. [CrossRef]

51. Zendelska, A.; Golomeova, M.; Blazev, K.; Krstev, B.; Golomeov, B.; Krstev, A. Adsorption of copper ions from aqueous solutions on natural zeolite. Environ. Prot. Eng. 2015, 41, 17-36. [CrossRef]

52. Shen, X.; Qiu, G.; Yue, C.; Guo, M.; Zhang, M. Multiple copper adsorption and regeneration by zeolite 4A synthesized from bauxite tailings. Environ. Sci. Pollut. Res. 2017, 24, 21829-21835. [CrossRef]

53. Wang, S.; Wu, H. Environmental-benign utilisation of fly ash as low-cost adsorbents. J. Hazard. Mater. 2006, 136, 482-501. [CrossRef]

54. Tuyen, N.T.K.; Nhan, D.N.T.; Nhat, T.T.; An, N.T.; Long, N.Q. Removal of copper (II) ion from aqueous solution using zeolite Y synthesized from rice husk ash: Equilibrium and kinetic study. AIP Publishing LLC 2017, 1878, 20016. [CrossRef]

55. Kajjumba, G.W.; Emik, S.; Öngen, A.; Özcan, H.K.; Aydın, S. Modelling of Adsorption Kinetic Processes-Errors, Theory and Application. In Advanced Sorption Process Applications; Edebali, S., Ed.; IntechOpen: London, UK, 2018. [CrossRef]

56. Visa, M.; Popa, N. Adsorption of heavy metals cations onto zeolite material from aqueous solution. J. Membr. Sci. Technol. 2015, 5, 133-140.

57. Lu, X.; Shi, D.; Chen, J. Sorption of $\mathrm{Cu}^{2+}$ and $\mathrm{Co}^{2+}$ using zeolite synthesized from coal gangue: Isotherm and kinetic studies. Environ. Earth Sci. 2017, 76, 591. [CrossRef]

58. Motsi, T.; Rowson, N.A.; Simmons, M.J.H. Adsorption of heavy metals from acid mine drainage by natural zeolite. Int. J. Miner. Process. 2009, 92, 42-48. [CrossRef]

59. Komnitsas, K.; Zaharaki, D.; Pyliotis, I.; Vamvuka, D.; Bartzas, G. Assessment of Pistachio Shell Biochar Quality and Its Potential for Adsorption of Heavy Metals. Waste Biomass Valorization 2015, 6, 805-816. [CrossRef]

60. Ren, X.; Xiao, L.; Qu, R.; Liu, S.; Ye, D.; Song, H.-G.; Wu, W.; Zheng, C.; Wu, X.; Gao, X. Synthesis and characterization of a single phase zeolite A using coal fly ash. RSC Adv. 2018, 8, 42200-42209. [CrossRef] 
61. Song, M.; Wei, Y.; Cai, S.; Yu, L.; Zhong, Z.; Jin, B. Study on adsorption properties and mechanism of Pb2+ with different carbon based adsorbents. Sci. Total. Environ. 2018, 618, 1416-1422. [CrossRef]

62. Townsend, R.P.; Coker, E.N. Chapter 11 Ion exchange in zeolites. Sci. Technol. Catal. 2006 2001, 137, 467-524. [CrossRef]

63. Chen, H.Y.; Chen, L.; Lin, J.; Tan, K.L.; Li, J. Copper Sites in Copper-Exchanged ZSM-5 for CO Activation and Methanol Synthesis: XPS and FTIR Studies. Inorg. Chem. 1997, 36, 1417-1423. [CrossRef]

64. Biesinger, M.C. Advanced analysis of copper X-ray photoelectron spectra. Surf. Interface Anal. 2017, 49, 1325-1334. [CrossRef]

65. Elzey, S.; Baltrusaitis, J.; Bian, S.-W.; Grassian, V.H. Formation of paratacamite nanomaterials via the conversion of aged and oxidized copper nanoparticles in hydrochloric acidic media. J. Mater. Chem. 2011, 21, 3162. [CrossRef]

66. Grünert, W.; Schlögl, R. Photoelectron Spectroscopy of Zeolites. In Characterization I; Karge, H.G., Weitkamp, J., Eds.; Springer: Berlin/Heidelberg, Germany, 2004; Volume 4, p. 492.

67. Zhang, M.; Yin, Q.; Ji, X.; Wang, F.; Gao, X.; Zhao, M. High and fast adsorption of Cd(II) and Pb(II) ions from aqueous solutions by a waste biomass based hydrogel. Sci. Rep. 2020, 10, 1-13. [CrossRef] [PubMed]

68. Payra, P.; Dutta, P.K. Zeolites: A Primer. In Handbook of Zeolites Science and Technology; Auerbach, S.M., Kathleen, A., Carrado, A., Dutta, P.K., Eds.; CRC Press: New York, NY, USA, 2003; pp. 1-19.

69. Pavelić, S.K.; Medica, J.S.; Gumbarević, D.; Filošević, A.; Pržulj, N.; Pavelić, K. Critical Review on Zeolite Clinoptilolite Safety and Medical Applications in vivo. Front. Pharmacol. 2018, 9, 9. [CrossRef]

(C) 2020 by the authors. Licensee MDPI, Basel, Switzerland. This article is an open access article distributed under the terms and conditions of the Creative Commons Attribution (CC BY) license (http://creativecommons.org/licenses/by/4.0/). 